\title{
Evaporative pad cooling model validation in a closed dairy cattle building
}

\author{
Felipe A. Obando ${ }^{a, *}$, Ana P. Montoya ${ }^{a}$, Jairo A. Osorio ${ }^{a}$, \\ Flávio A. Damasceno ${ }^{b}$, Tomas Norton ${ }^{c}$ \\ ${ }^{a}$ Facultad de Ciencias Agrarias, Universidad Nacional de Colombia, Medellín, Antioquia, Colombia \\ ${ }^{\mathrm{b}}$ Departamento de Engenharia, Universidade Federal de Lauras, Lauras, Minas Gerais, Brazil \\ ${ }^{c}$ Division of Measure, Model \& Manage Bioresponses (M3-Biores), KU Leuven, Kasteelpark Arenberg 30, 3001 \\ Leuven, Belgium
}

Keywords:

Cellulose pad cooling

Heat and mass transfer coefficients

Evaporative pad cooling model

Direct evaporative cooling

Closed dairy cattle building
A mathematical model of an evaporative pad cooling system to predict the dry-bulb temperature and relative humidity of air exiting the pad, its cooling efficiency and the water requirements for agricultural buildings was derived from first principles using mass and energy balances. The model uses the geometry of the evaporative pad as characteristic parameters and the water temperature, dry-bulb temperature and relative humidity of the outside air as primary boundary conditions. The model was validated with data from wind tunnel tests and field experiments on a closed dairy cattle building using an evaporative pad cooling system. These data also enabled new expressions for heat and mass transfer coefficients of a cellulose cooling pad to be developed and validated. The resulting model accurately predicted the main output variables in the closed dairy cattle building, with the prediction error falling inside the accuracy of the sensors used to measure the environmental variables $\left( \pm 0.5{ }^{\circ} \mathrm{C}\right.$ and $\pm 3 \%$ for dry-bulb temperature and relative humidity, respectively). The effect of pad water temperature on the output variables was obtained with the developed model, allowing to propose the pad water temperature as an effective manipulated variable for designing an evaporative pad cooling control system. It was found that, for each Celsius degree that the water temperature decreased below the input wetbulb temperature, the output dry-bulb temperature decreased by $0.7{ }^{\circ} \mathrm{C}$ and the output relative humidity increased by $1 \%$.

\section{Introduction}

In recent years, climate change has increased the magnitude and duration of dry and wet seasons globally. This has contributed to increasing the use of agricultural facilities where it is possible to modify or control the microenvironmental conditions of plants/animals throughout the year. As a result research efforts have increased on the design of lowcost and environmentally friendly technologies to better condition the indoor temperature of plant/animal facilities. 


\begin{tabular}{|c|c|c|c|}
\hline \multicolumn{2}{|c|}{ Nomenclature } & $a_{1}, a_{2}$ & Coefficients in equations ( $5 a$ and $5 b$ ) \\
\hline & & $A_{s}$ & Wetted surface area $\left[\mathrm{m}^{2}\right]$ \\
\hline \multicolumn{2}{|c|}{ Dimensionless number } & $b_{1}, b_{2}$ & Exponents of the relation $\left(l_{\mathrm{e}} / \mathrm{L}\right)$ in Table 2 \\
\hline $\mathrm{Nu}$ & Nusselt number & $c_{1}, c_{2}$ & Exponents of the Reynolds number in equations \\
\hline $\operatorname{Pr}$ & Prandtl number & & (5a and $5 b)$ \\
\hline Re & Reynolds number & $c_{p}$ & Specific heat $\left[\mathrm{kg}^{-1} \mathrm{~K}^{-1}\right]$ \\
\hline Sc & Schmidt number & $D_{A B}$ & Mass diffusion coefficient $\left[\mathrm{m}^{2} \mathrm{~s}^{-1}\right]$ \\
\hline Sh & Sherwood number & $\mathrm{H}$ & Cooling pad height $[\mathrm{m}]$ \\
\hline \multirow{2}{*}{\multicolumn{2}{|c|}{ Greek symbols }} & $\mathrm{h}$ & Enthalpy of moist air $\left[\mathrm{Jg}^{-1}\right]$ \\
\hline & & $h_{f g}$ & Enthalpy of vaporisation $\left[\mathrm{J} \mathrm{kg}^{-1}\right]$ \\
\hline$\alpha$ & & $h_{f}$ & Enthalpy of liquid water saturate $\left[\mathrm{J} \mathrm{kg}^{-1}\right]$ \\
\hline$\eta$ & $\begin{array}{l}\text { Cooling efficiency }[\%] \\
\text { Dynamic viscosity }\left[\mathrm{kg} \mathrm{s} \mathrm{m}^{-1}\right]\end{array}$ & $h_{g}$ & Enthalpy of saturated water vapour $\left[\mathrm{Jg}^{-1}\right]$ \\
\hline$\mu$ & $\begin{array}{l}\text { Dynamic viscosity }\left[\mathrm{kg} \mathrm{s} \mathrm{m}^{2}\right] \\
\text { Kinematic viscosity }\left[\mathrm{m}^{2} \mathrm{~s}^{-1}\right]\end{array}$ & $h_{H}$ & Heat transfer coefficient $\left[\mathrm{W} \mathrm{m}^{-2}\right]$ \\
\hline$\omega$ & Specific humidity $\left[\mathrm{kg}_{\mathrm{H} 2 \mathrm{O} \mathrm{kg}^{-1} \text { moist air] }}\right.$ & $h_{M}$ & Mass transfer coefficient $\left[\mathrm{m} \mathrm{s}^{-1}\right]$ \\
\hline$\varphi$ & $\begin{array}{l}\text { Relative humidity [\%] } \\
\text { [\% moist arr] }\end{array}$ & $k$ & Thermal conductivity $\left[\mathrm{W} \mathrm{m}^{-1} \mathrm{~K}^{-1}\right]$ \\
\hline$\rho$ & Density $\left[\mathrm{kg} \mathrm{m}^{-3}\right]$ & L & Cooling pad thickness [m] \\
\hline$\zeta$ & Specific wetted surface area $\left[\mathrm{m}^{2} \mathrm{~m}^{-3}\right]$ & $l_{m}$ & Logarithmic mean \\
\hline \multicolumn{2}{|c|}{ Subscript/superscript } & $m$ & Exponent of the Prandtl and Schmidt numbers in \\
\hline a & Dry air & & equations ( $5 a$ and $5 b)$ \\
\hline$d b$ & Dry-bulb & $\mathrm{N}$ & Number of partitions \\
\hline$e$ & Evaporation & $n$ & Exponent of the Prandtl and Schmidt relationship \\
\hline$f$ & Mean boundary film layer & & in equations ( $5 a$ and $5 b)$ \\
\hline i & Input & $P$ & Pressure $[\mathrm{kPa}]$ \\
\hline 0 & Output & $Q_{\text {lat }}$ & Latent heat $[\mathrm{W}]$ \\
\hline s & Surface & $Q_{s e n}$ & Sensible heat [W] \\
\hline sat & Saturation state & $\mathrm{T}$ & Temperature $\left[{ }^{\circ} \mathrm{C}\right]$ \\
\hline$v$ & Vapour & u & Air velocity $\left[\mathrm{m} \mathrm{s}^{-1}\right]$ \\
\hline$w$ & Water & $\mathrm{V}$ & Volume $\left[\mathrm{m}^{3}\right]$ \\
\hline$w b$ & Wet-bulb & W & Cooling pad width [m] \\
\hline \multirow{2}{*}{\multicolumn{2}{|c|}{ Variables }} & $x$ & Spatial coordinate $[\mathrm{m}]$ \\
\hline & & & Distance between wave crests [mm] \\
\hline$m_{a}$ & Humid air mass flow rate $\left[\mathrm{kg}_{\text {moist air }} \mathrm{s}^{-1}\right]$ & $z$ & Wave height $[\mathrm{mm}]$ \\
\hline$m_{e}$ & Evaporated water mass flow rate $\left[\mathrm{kg} \mathrm{s}^{-1}\right]$ & & \\
\hline
\end{tabular}

Although there are many methods available, the evaporative pad cooling techniques have continuously been demonstrated as effective (Chen et al., 2011; Malli et al., 2011; Shukla et al., 2008).

Evaporative pad cooling comprises the forcing of air through a water saturated porous medium while the water is being recirculated by a hydraulic pump. When the air passes through the pad, its temperature decreases due to sensible heat transfer caused by the air-water energy gradient. As a result, the water gains latent heat and evaporates due to the specific humidity differences. A decrease in the output air temperature with a concomitant increase in the relative humidity is achieved in this process. It is therefore necessary to optimise the design and control of the evaporative pad to achieve appropriate dry-bulb temperature and relative humidity set-points. However, to achieve this experimentally can be expensive and time-consuming and a mathematical pad cooling model can be far more effective and efficient for this purpose.

Over the years a number of pad cooling models have been developed. Halasz (1998) proposed a non-dimensional model for any evaporative cooling device based on the transformation of differential equations to a non-dimensional form. Al-Ismaili et al. (2010) validated this model in a greenhouse equipped with a cellulose evaporative pad cooling system. Other authors have proposed simplified mathematical explicit models to compute the efficiency of pad cooling using different materials, e.g. Camargo et al. (2005b) and Camargo et al. (2005a) for cellulose pad cooling, de Carvalho et al. (2006) for expanded clay pad cooling and Wu et al. (2009b) for Glasdek ${ }^{\circledR}$ pad cooling.

More complex models based on the Navier-Stokes equations such as Wu et al. (2009a) for Glasdek ${ }^{\circledR}$ pad cooling and Osorio Saraz et al. (2012) for expanded clay pad cooling have been developed. Fouda and Melikyan (2011) simplified the model proposed by Wu et al. (2009a) and found it to be useful for designing direct evaporative coolers. More recently, Kovacevic and Sourbron (2017) proposed and validated a differential equation based model for a parallel plate evaporative cooler. While it is clear that many levels of sophistication exist in the models of pad cooling systems, for any of them to be accurate and effective the heat and mass transfer coefficients must be correctly estimated. This is a challenge that is specific to the type of cooling pad and material utilised. Moreover, the above models have not been exploited to analyse the temperature effect of the water in the pad on the output dry-bulb 
temperature and relative humidity, which is a key requirement for pad cooling system design.

Many of the currently used expressions to compute heat and mass transfer coefficients are based on correlations for heat and mass transfer by forced convection flow passing over a cylinder, as found by Hilpert (see Incropera et al., 2011), where the Nusselt number $(\mathrm{Nu})$ expressed as a function of the Reynolds (Re) and Prandtl ( $\mathrm{Pr}$ ) numbers was used to computed the heat transfer coefficients; and the Sherwood number (Sh) expressed as a function of the Reynolds (Re) and Schimidt (Sc) numbers was used for the mass transfer coefficients. Dowdy and Karabash (1987) added a specific length to these expressions to compute the transfer coefficients for a cellulose pad cooling; linking the wet area surface of the pad. These results were then implemented in pad cooling models developed by other researchers, Camargo et al. (2005a,b), Wu et al. (2009b), and Al-Ismaili et al. (2010). Following this He et al. (2014) added a term relating the input wet-bulb, dry-bulb and water temperature to the expressions proposed by Dowdy and Karabash (1987) but accuracy was not considerably improved.

Alternative approaches to that of the Hilpert correlations have also been proposed in the literature. An expression to compute the transfer coefficients in terms of a wetted surface area and air velocity was found by Wu et al. (2009b). Franco et al. (2014) found a similar expression but adding the specific length of the pad cooling. Furthermore, Liao et al. (1998) and Liao and Chiu (2002) proposed expressions based on the correlation of Zukauskas (Incropera et al., 2011), which are similar to Hilpert, adding the specific length of the pad cooling as well. de Carvalho et al. (2006) used the Coulburn factors (Incropera et al., 2011) for computing the transfer coefficients for spherical material like expanded clay.

This paper presents the developments of a mathematical model to simulate an evaporative pad cooling system. New correlation expressions are proposed to accurately compute the transfer coefficients for cellulose pad cooling improving the prediction of output temperature and relative humidity. This model is then validated through wind tunnel tests and field testing with closed dairy cattle building equipped with evaporative cooling pad. Finally, the water temperature effect on the pad output dry-bulb temperature and output relative humidity was analysed using the proposed mathematical model.

\section{Materials and methods}

\subsection{Evaporative pad cooling mathematical model}

The humid air that flows through the pad cooling (Fig. 1) is assumed as a mixture between two ideal gases: dry air and water vapour. The humid air enters the pad with velocity $u$, dry-bulb temperature $T_{d b_{i}}$ and specific humidity $\omega_{i}$ and leaves with a dry-bulb temperature $T_{d b_{0}}$ and specific humidity $\omega_{0}$. It is assumed that the air velocity $u$ and the humid air mass flow rate $\dot{m}_{a}$ are constants through the cooling pad.

As is described in Appendix A, if steady-state conditions are considered, a mass and energy balance over an infinitesimal wetted surface area $\left(\mathrm{dA}_{\mathrm{s}}\right)$ at the interior of the pad cooling

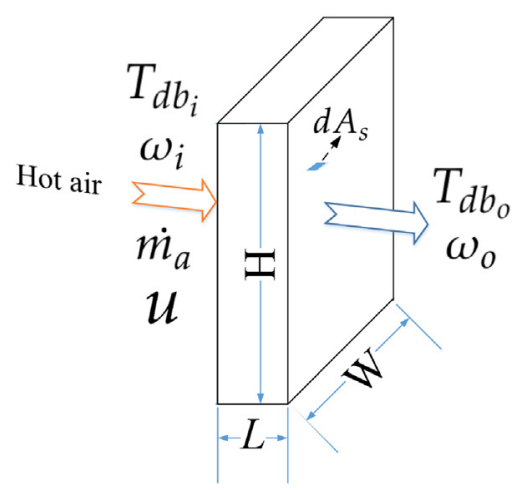

Fig. 1 - Evaporative pad cooling model. Input and output variables associate with the pad cooling operation.

leads to a system of ordinary differential equations (ODEs) (1) to compute the change in the dry-bulb temperature $\left(T_{d b}\right)$ and specific humidity $(\omega)$ of the humid air through the pad cooling. This allows the behaviour of the main output variables of the cooling pad to be determined: dry-bulb temperature, relative humidity and cooling efficiency and also to determine the effect of water temperature on them.

$\left\{\begin{array}{l}\frac{\mathrm{d} T_{d b}}{\mathrm{~d} x}=\frac{\zeta \mathrm{WH}\left(\mathrm{T}_{s}-\mathrm{T}_{d b}\right)\left(h_{H}+h_{\mathrm{M}} c_{p v_{a 0} \mathrm{C}}\left(\rho_{v_{\mathrm{s}}}-\rho_{v}\right)\right)}{\dot{m}_{a}\left(c_{p a}+\omega c_{p v_{a 0^{\circ} \mathrm{C}}}\right)} \\ \frac{\mathrm{d} \omega}{\mathrm{d} x}=\frac{\zeta \mathrm{WH} h_{\mathrm{M}} \rho_{a}\left(\rho_{v_{\mathrm{s}}}-\rho_{v}\right)}{\dot{m}_{a}} \\ \text { With initial conditions } \mathrm{T}_{d b}(0)=\mathrm{T}_{d b_{i}} \text { and } \omega(0)=\omega_{\mathrm{i}} \\ \text { For } 0 \leq x \leq \mathrm{L}\end{array}\right.$

According to Liao et al. (1998), since the water is recirculated constantly in the pad cooling, it reaches a thermal equilibrium with the humid air flowing through the cooling pad. Therefore, the wetted surface temperature can be considered equal to the air input wet-bulb temperature, that is, $\mathrm{T}_{\mathrm{s}}=\mathrm{T}_{w b_{i}}$.

The specific wetted surface area $(\zeta)$ and the heat and mass transfer coefficients, $h_{H}$ and $h_{M}$, depend mainly on the pad cooling material. The cellulose pad cooling has been broadly studied, and its specific wetted surface area value has been already estimated (Franco et al., 2014, 2010; He et al., 2014). The corrugated waves forming the channels for air flow through the cellulose pad have three main dimensions: the channel inclination angle, the wave height ( $\mathrm{z}$ ) and the distance between wave crests (y). These dimensions are frequently considered constants, however, they depend on the channel inclination angle. The expression (2) allows the $\zeta$ value to be computed with more precision by considering the differences in the geometry of the waves of the corrugated cellulose pad. Table 1 shows a summary of the parameters of the analysed evaporative cooling.

$\zeta=2\left(\frac{\sqrt{\left(\frac{y_{1}}{2}\right)^{2}+\left(z_{1}\right)^{2}}}{y_{1} * z_{1}}+\frac{\sqrt{\left(\frac{y_{2}}{2}\right)^{2}+\left(z_{2}\right)^{2}}}{y_{2} * z_{2}}\right)$ 
Table 1 - Characteristics dimensions of the cellulose cooling pad analysed. Celdek ${ }^{\circledR}$ 7060-15 cellulose cooling pad (Munters

Brasil Industria e Comércio Ltda, Araucária, Brazil) tested in the wind tunnel (first row) and cellulose cooling pad with $45^{\circ}$

$15^{\circ}$ angles (CIABRAPE, Empresa Brasileira de Papéis Especiais, Campinas, Brazil) installed in the closed dairy cattle building (second row).

\begin{tabular}{lcccccccccc} 
Angles $\left[^{\circ}\right]$ & $y_{1}[\mathrm{~mm}]$ & $y_{2}[\mathrm{~mm}]$ & $z_{1}[\mathrm{~mm}]$ & $z_{2}[\mathrm{~mm}]$ & $L[\mathrm{~m}]$ & $H[\mathrm{~m}]$ & $\mathrm{W}[\mathrm{m}]$ & $l_{e}[\mathrm{~mm}]$ & $\zeta\left[\mathrm{m}^{2} / \mathrm{m}^{3}\right]$ & $A_{s}\left[\mathrm{~m}^{2}\right]$ \\
\hline $45-15$ & 22.6 & 16.4 & 6.2 & 7.0 & 0.1 & 0.5 & 0.5 & 2.7 & 372.6 & 9.4 \\
$45-15$ & 25 & 30 & 7.5 & 8.0 & 0.1 & 3.6 & 18 & 3.4 & 297.2 & 1925.6 \\
\hline
\end{tabular}

\subsection{Heat and mass transfer coefficients}

The heat and mass transfer coefficients could be approximated by equations (3) and (4) (Dowdy and Karabash, 1987), in terms of the logarithmic mean temperature difference $\left(\Delta \mathrm{T}_{l m}\right)$ and the logarithmic mean density difference $\left(\Delta \rho_{v_{l m}}\right)$, due to considerable differences of temperature and specific humidity between the input and output humid air of the cooling pad (Incropera et al., 2011).

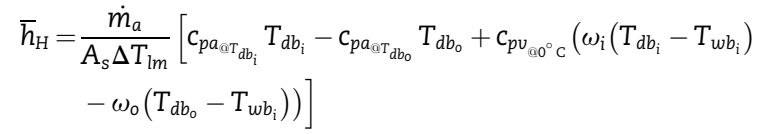

$\bar{h}_{\mathrm{M}}=\frac{\dot{m}_{a}}{A_{s} \Delta \rho_{v_{l m}}}\left(\omega_{0}-\omega_{i}\right)$

where,

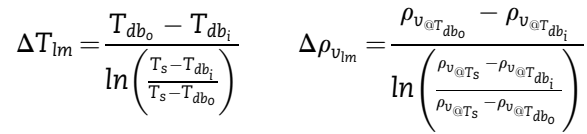

The correlation of Hilper (equation (5) with $m=1 / 3$ and $n=0$ ) and the correlation of Zukauskas (equation (5) with $n=$ 1/4) have been used frequently to relate the heat and mass transfer coefficients with some geometric and operational parameters of the evaporative cooling pad.

$\mathrm{Nu}=a_{1} \operatorname{Re}^{c_{1}} \operatorname{Pr}^{m}\left(\frac{\operatorname{Pr}}{\operatorname{Pr}_{\mathrm{s}}}\right)^{n}$

$S h=a_{2} \operatorname{Re}^{c_{2}} S c^{m}\left(\frac{S c}{S c_{s}}\right)^{n}$

A geometric correction factor, $\left(l_{e} / L\right)^{b}$, has been added to these equations in multiple cooling pad research studies with improved results (Liao et al., 1998). $l_{e}$ is known as the characteristic length and is defined as the ratio between volume and wetted surface area of the pad cooling $\left(l_{e}=V / A_{s}\right)$. For the correlation of Zukauskas, the exponent $m$ is equal to 0.37 for $\operatorname{Pr} \lesssim 10$ or 0.36 for $\operatorname{Pr} \gtrsim 10$ (Incropera et al., 2011). The $a, b$ and $c$ parameters should be adjusted as a function of the cooling pad material. The coefficients for some cooling pad materials found in several research studies are summarised in Table 2.

$\mathrm{Nu}$ and Sh are the Nusselt and Sherwood dimensionless numbers which correlate geometrical and operative parameters of the evaporative pad cooling system and flow air properties with the heat and mass transfer coefficient through Reynolds (Re), Prandtl ( $\mathrm{Pr}$ ) and Schmidt (Sc) dimensionless numbers. Nu, Sh and Re should be computed using the characteristic length $l_{e}$. The thermodynamics properties of the air used to compute those dimensional numbers should be evaluated at the mean boundary film layer temperature, $T_{\mathrm{f}}=$ $\left(T_{d b}+T_{s}\right) / 2$, for the correlation of Hilper and at $T_{d b}$ for the correlation of Zukauskas, except for the terms $\mathrm{Pr}_{\mathrm{s}}$ and $\mathrm{Sc}_{\mathrm{S}}$ which should be evaluated at $\mathrm{T}_{\mathrm{s}}$ (Incropera et al., 2011).

To validate the developed evaporative cooling pad mathematical model, experimental data obtained in two scenarios were used. In the first scenario, a cellulose cooling pad was tested in an open circuit wind tunnel, while in the second scenario, experimental data were collected from a closed dairy cattle building that used cellulose evaporative cooling pads as micro-environmental air conditioning system. Both correlations, Hilpert and Zukauskas, where used to compute the heat and mass transfer coefficients in order to select the one that provides the best model predictions. Using the wind tunnel experimental data, coefficients for the correlation of Hilper and Zukauskas were computed applying equations (3) and (4).

\subsection{Open circuit wind tunnel test}

The setup depicted in Fig. 2a was employed to test a Celdek $\mathbb{R}$ 7060-15 cellulose cooling pad (Munters Brasil Industria e

Table 2 - Parameters used to compute the heat and mass transfer coefficients by equation (5) for different pad materials. The symbol "-" is used for research that does not use the equation related with the parameters.

\begin{tabular}{|c|c|c|c|c|c|c|c|c|}
\hline Material & $a_{1}$ & $b_{1}$ & $c_{1}$ & $a_{2}$ & $b_{2}$ & $c_{2}$ & Correlation & Research \\
\hline Aspen fibres & 1.77 & 0.63 & 0.8 & 1.37 & 0.63 & 0.8 & Hilper & (Dowdy \& Handy, 1986) \\
\hline Rigid cellulose paper & 0.1 & 0.12 & 0.8 & 0.08 & 0.12 & 0.8 & Hilper & (Dowdy \& Karabash, 1987) \\
\hline Coir fibre & 0.025 & 0.55 & 0.96 & 0.079 & 0.55 & 0.95 & Zukauskas & (Liao et al., 1998) \\
\hline Nonwoven fabric perforated & 0.0053 & 0.46 & 0.75 & 0.0028 & 0.46 & 0.75 & Zukauskas & (Liao et al., 1998) \\
\hline Coarse fabric PVC sponge mesh & 0.0004 & 0.45 & 0.89 & 0.0003 & 0.45 & 0.89 & Zukauskas & (Liao \& Chiu, 2002) \\
\hline Fine fabric PVC sponge mesh & 0.0047 & 0.19 & 0.43 & 0.0017 & 0.19 & 0.43 & Zukauskas & (Liao \& Chiu, 2002) \\
\hline Cellulose media & 0.192 & 0.191 & 0.682 & - & - & - & Hilper & (He et al., 2014) \\
\hline PVC media & 0.210 & 1.113 & 0.223 & - & - & - & Hilper & (He et al., 2014) \\
\hline Cellulose pads & 0.172 & 0.32 & 0.85 & 0.141 & 0.32 & 0.85 & Hilper & (Franco et al., 2010) \\
\hline Cellulose and plastic pads & 0.091 & 0.32 & 0.975 & 0.036 & 0.32 & 0.975 & Hilper & (Franco et al., 2014) \\
\hline
\end{tabular}




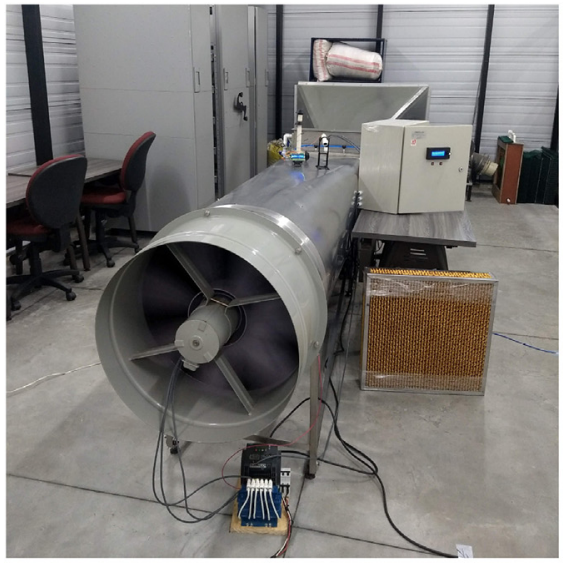

(a)

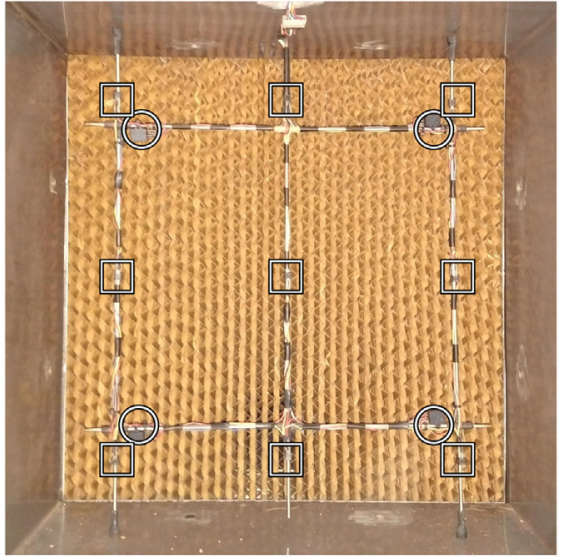

(b)

Fig. 2 - Open circuit wind tunnel used for evaporative pad cooling tests. (a) - Open circuit wind tunnel. (b) - Cellulose pad and air temperature (square) and relative humidity (circle) sensors locations.

Comércio Ltda, Araucária, Brazil) with dimensions $0.5 \times 0.5 \times$ $0.1 \mathrm{~m}$ (length $\times$ width $\times$ thickness). The wind tunnel is located at the Universidad Nacional de Colombia in Medellín, Colombia. The wind tunnel has a SIEMENS three-phase exhaust fan (2CC2-634-5YB6T) controlled with a $2 \mathrm{hp}$ SIEMENS SINAMICS V20 variable frequency drive. The air velocity was varied between 0.5 and $3.5 \mathrm{~m} \mathrm{~s}^{-1}$ in $0.5 \mathrm{~m} \mathrm{~s}^{-1}$ increments. The cooling pad was tested using three water flow values: $1.1,3.1$ and $5.1 \mathrm{~L} \mathrm{~min}^{-1}$, which corresponds to values under, equal to and above the minimum value recommended by ASABE (2008) (6.2 $\mathrm{L} \mathrm{min}^{-1} \mathrm{~m}^{-1}$ ) for cellulose pad. Additionally, in order to quantify the pad water evaporation rate, a test was made by setting the air velocity and water flow constants at $1 \mathrm{~m} \mathrm{~s}^{-1}$ and $3.1 \mathrm{~L} \mathrm{~min}^{-1}$, respectively. The temperature and relative humidity were measured at $0.15 \mathrm{~m}$ before and after the cooling pad using a network of nine DS18B20 digital thermometers (Maxim Integrated Products, Sunnyvale, USA) with accuracy of $\pm 0.5^{\circ} \mathrm{C}$ over the measurement range of $-10{ }^{\circ} \mathrm{C}$ to $+85^{\circ} \mathrm{C}$, and on each side, four SHT21 relative humidity sensors (Sensirion, Staefa, Switzerland) with accuracy of $\pm 2 \%$ over the measurement range of $0 \%-100 \%$, distributed as depicted in Fig. $2 \mathrm{~b}$. The air velocity was measured at $0.20 \mathrm{~m}$ before the pad using a Windosonic ultrasonic wind sensor (Gill Instruments Limited, Lymington, UK) with accuracy of $\pm 2 \%$ at $12 \mathrm{~m} \mathrm{~s}^{-1}$ and a measurement range of $0-60 \mathrm{~m} \mathrm{~s}^{-1}$. The water flow was measured using a YS-S201 Hall effect flow meter (Dongguan Yifa Plastic Products Co., Dongguan, China) with accuracy of $\pm 5 \%$ of the measurement over a range of $1-30 \mathrm{~L} \mathrm{~min}^{-1}$. The input, output and reservoir water temperature were measured with watertight DS18B20 digital thermometer. The pad pressure drop was measured using a PX653-05D5V differential pressure transmitter (Omega Engineering, Norwalk, USA) with accuracy of $0.3 \%$ of full scale over a measurement range of $0-1.25 \mathrm{kPa}$, connected to the wind tunnel piezometric ring at input and output of the pad cooling. The measurements were collected every $10 \mathrm{~s}$ using an Arduino mega 2560 (www.arduino.cc) as interface to send the data over bluetooth to a desktop computer (Hewlett-Packard Z44 workstation) running a program developed in the opensource software Processing (processing.org) to visualise, process and store the data. By averaging the measurements of temperature and relative humidity on each side of the pad cooling system, the air temperature and relative humidity at input and output of the pad were then obtained.

\subsection{Dairy cattle building}

Measurements of temperature, relative humidity and air velocity were collected for 5 days from an evaporative pad cooling system of a closed dairy cattle building (Fig. 3) with external length of $55 \mathrm{~m}$, width of $28 \mathrm{~m}$ and height of $5 \mathrm{~m}$ at the ridge. The facility is located in the city of Viçosa, Minas Gerais, Brasil (latitude $20^{\circ} 46^{\prime} 41^{\prime \prime} \mathrm{S}$, longitude $42^{\circ} 48^{\prime} 57^{\prime \prime} \mathrm{W}$ and altitude $657 \mathrm{~m}$ ). The tests were made between February 26 and March 7 of 2019 with average, minimum and maximum values of 23.1, 18.2 and $33.5^{\circ} \mathrm{C}$ for dry-bulb air temperature; and 81, 36 and $97 \%$ for relative humidity, respectively. The pad cooling system is divided in 5 sections, each one with dimensions of $3.6 \times$ $3.6 \times 0.1 \mathrm{~m}$ (length $\times$ width $\times$ thickness). It used a cellulose cooling pad with $45^{\circ} \times 15^{\circ}$ angles (CIABRAPE, Empresa Brasileira de Papéis Especiais, Campinas, Brazil). The air velocity was driven by five exhaust fans with $3.5 \mathrm{~m}$ diameter, each one operated with a SEW-EURODRIVER motor of $1.5 \mathrm{~kW}$. The temperature and relative humidity data were collected using HT-500 dataloggers (Instrutherm, São Paulo, Brazil) with accuracy of $\pm 1{ }^{\circ} \mathrm{C}$ over a measurement range of $-40{ }^{\circ} \mathrm{C}$ to $70{ }^{\circ} \mathrm{C}$, and $\pm 3 \%$ over a measurement range of $0 \%-100 \%$. These dataloggers were located at the input and output of the pad cooling and distributed uniformly along 5 locations inside the dairy cattle building and positioned $2 \mathrm{~m}$ above the floor and $1 \mathrm{~m}$ before and after the pad. The air velocity was measured with a TAFR-190 hot wire anemometer (Instrutherm, São Paulo, Brazil) with accuracy of $\pm 5 \%$ of the measure over a measurement range of $0.1-25 \mathrm{~m} \mathrm{~s}^{-1}$. The input, output and reservoir water temperature were measured using a $\mathrm{HOBO}$ U12-006 4 channel datalogger and TMC20-HD temperature probes (Onset Computer Corporation, Bourne, USA) with 


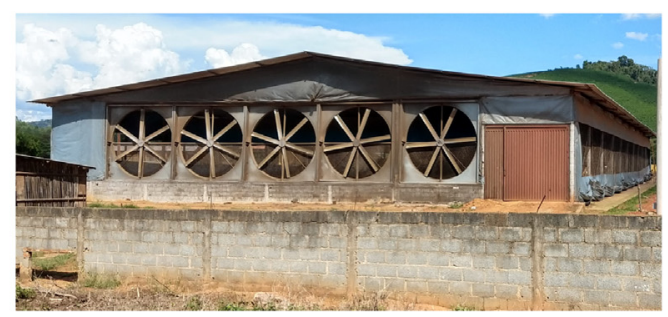

(a)

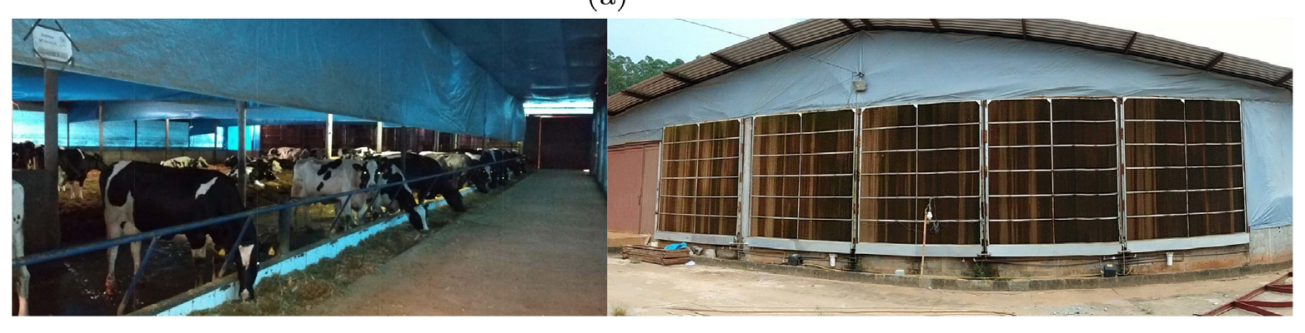

(b)

(c)

Fig. 3 - Closed dairy cattle building with evaporative pad cooling system. a - Exhaust fans. b - Inside of the closed dairy cattle building. c - Evaporative pad cooling system.

accuracy of $\pm 0.25{ }^{\circ} \mathrm{C}$ over a measurement range of $-40{ }^{\circ} \mathrm{C}$ to $50{ }^{\circ} \mathrm{C}$.

\subsection{Model validation}

The model solution using each of the correlations presented here were compared with the correlations of Hilper proposed by Dowdy and Karabash (1987) and Franco et al. (2010). For this, the Bland and Altman (B\&A) plot (Giavarina, 2015) was employed to show the agreement between measurements and model predictions for each of the correlations used. The agreement interval includes the $95 \%$ of differences between the measurements and the model predictions, and is defined, for non-normally distributed variables, as the interval between the 2.5th and 97.5th percentile, that is, the median $\pm 1.45 *$ interquartile range. The accuracy of the model predictions are quantified by the Root Mean Square Error (RMSE); it indicates how close the experimental measurements are to the model's predicted values.

The proposed model was solved using a 4th order RungeKutta (RK4) numerical solution method with 250 partitions of the pad thickness (See Appendix B). The MATLAB software was employed to solve the equations and post-processing routines. The thermodynamics properties of the dry air and water vapour used were calculated using the equations presented in appendix Appendix $C$.

The cooling efficiency $(\eta)$ was defined in terms of the variation between the $T_{d b_{o}}$ and $T_{w b_{i}}$ with respect to $T_{d b_{i}}$ and it was computed using equation (6). This expression was derived by assuming that the maximum heat and mass transfer inside the cooling pad occurred when the exiting humid air is saturated at a dry-bulb temperature equal to the input wet-bulb temperature through an adiabatic process (ASHRAE, 2011).

$\eta=\frac{\mathrm{T}_{d b_{i}}-\mathrm{T}_{d b_{0}}}{\mathrm{~T}_{d b_{i}}-\mathrm{T}_{w b_{i}}}$

\section{Results and discussions}

\subsection{Heat and mass transfer coefficients}

Equations (3) and (4) were used to compute the average heat and mass transfer coefficients from the wind tunnel test results. An iterative weighted least squares algorithm was used to find the optimal average transfer coefficients using both the correlations of Hilper and the correlations of Zukauskas, thereby obtaining equations (7) and (8), respectively. There are small differences (less than 0.012) between the computed coefficients for both correlations mainly because the terms $\mathrm{Pr} / \mathrm{Pr}_{\mathrm{s}}$ and $\mathrm{Sc} / \mathrm{Sc}_{\mathrm{s}}$ in the correlations of Zukauskas are almost one (0.99). The RMSE values computed with both equations are equal (0.18), suggesting that either can be used. Therefore, hereafter only the results for expression (7) will be presented graphically. The obtained expressions allow the heat and mass transfer coefficients to be computed from the input environmental and operative conditions of the evaporative pad cooling system.

$$
\begin{aligned}
& \mathrm{Nu}=1.042\left(\frac{l_{e}}{L}\right)^{0.426} \operatorname{Re}^{0.617} \operatorname{Pr}^{\frac{1}{3}} \\
& \mathrm{Sh}=0.385\left(\frac{l_{e}}{L}\right)^{0.513} \operatorname{Re}^{0.724} \mathrm{Sc}^{\frac{1}{3}} \\
& \mathrm{Nu}=1.054\left(\frac{l_{e}}{L}\right)^{0.425} \operatorname{Re}^{0.617} \operatorname{Pr}^{0.37}\left(\frac{\mathrm{Pr}}{\mathrm{Pr}_{s}}\right)^{\frac{1}{4}} \\
& \mathrm{Sh}=0.395\left(\frac{l_{e}}{L}\right)^{0.516} \operatorname{Re}^{0.724} \mathrm{Sc}^{0.37}\left(\frac{\mathrm{Sc}}{\mathrm{Sc}_{s}}\right)^{\frac{1}{4}}
\end{aligned}
$$

Figure 4 shows the relation between the transfer coefficients and the air velocity and input dry-bulb temperature. 
It is also shown how those coefficients are proportional to the air speed, while the variation of the input dry-bulb temperature has a negligible effect. Indeed, as the thermodynamics properties of the air used in expression (7) are evaluated at the boundary film temperature, the variation of the water input temperature has also an insignificant effect on the heat and mass transfer coefficients.

The expressions (7) and (8) describe adequately the heat and mass transfer coefficient dynamics, with a slight deviation for the heat transfer coefficient at $0.5 \mathrm{~m} \mathrm{~s}^{-1}$, obtaining values higher than the ones computed with equation (3). This causes an underestimation of $T_{d b}$ predictions at this low air velocity.

\subsection{Model validation with tunnel tests}

Figure 5 shows the behaviour of the main output variables of the pad cooling system: dry-bulb temperature $\left(T_{d b_{0}}\right)$, relative humidity $\left(\varphi_{0}\right)$ and efficiency $(\eta)$ with respect to air velocity. The model predictions using the expressions (7) and (8) can be considered equal and are very close to the experimental data for almost all the air velocity values. As was mentioned early, the underestimation of the predicted $T_{d b_{0}}$ (Fig. 5a) at low air velocity causes an overestimation of predicted $\varphi_{\mathrm{o}}$ (Fig. 5b) and $\eta$ (Fig. 5c) values. The pad manufacturer cooling efficiency data are also plotted in Fig. 5c. The experimental data are up to $8 \%$ above the manufacturers curve. All the model predictions have the same behaviour: the efficiency decreases with increasing air velocity.

The RMSE values (Table 3) can be considered as an estimation of average prediction errors. The model solution with correlation (7) or (8) predicts the output dry-bulb temperature $\left(T_{d b_{0}}\right)$, output relative humidity $\left(\varphi_{0}\right)$ and efficiency $(\eta)$ with an average error of $\pm 0.06{ }^{\circ} \mathrm{C}, \pm 0.36 \%$ and $\pm 1.19 \%$, respectively. The RMSE values do not vary significantly with the water flow changes; it means that the estimation of heat and mass transfer coefficients is not affected by the water flow, as was stated by Franco et al. (2010). The average RMSE values of $T_{d b_{0}}$ and $\varphi_{0}$ fall inside the accuracy range of sensors used and confirm that the model predictions with the correlations (7) or (8) describe the experimental data with good precision. Consequently, independently of the method used to compute the heat and mass transfer coefficients, the cooling pad mathematical model proposed here describes the dynamic behaviour of the evaporative cooling satisfactorily.

The agreement between measurements and model predictions was analysed using the Bland and Altman plot (Fig. 6). The agreement intervals (dashed lines) for the predictions of $\mathrm{T}_{d b_{o}}$ (Fig. 6a), $\varphi_{o}$ (Fig. 6b) and $\eta$ (Fig. 6c) using the correlations (7) are close to the accuracy range of the sensors employed and slightly above the average RMSE values. These agreement intervals are also narrower than using the correlations of Franco et al. (2010) (Fig. 6d-f) and Dowdy and Karabash (1987) (Fig. 6g-i). Additionally, the $p$-values computed using the

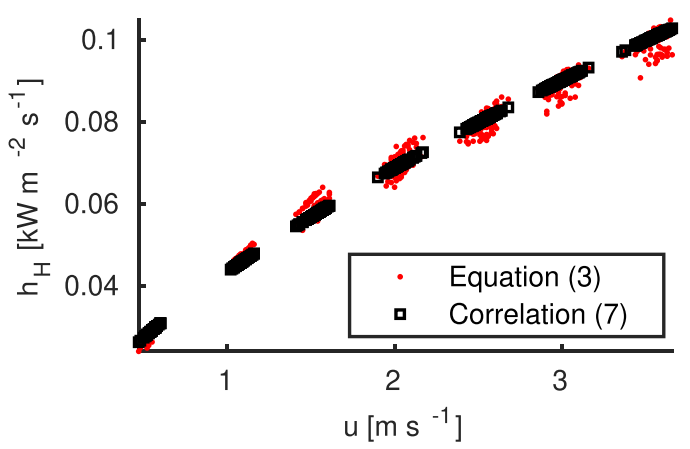

(a)

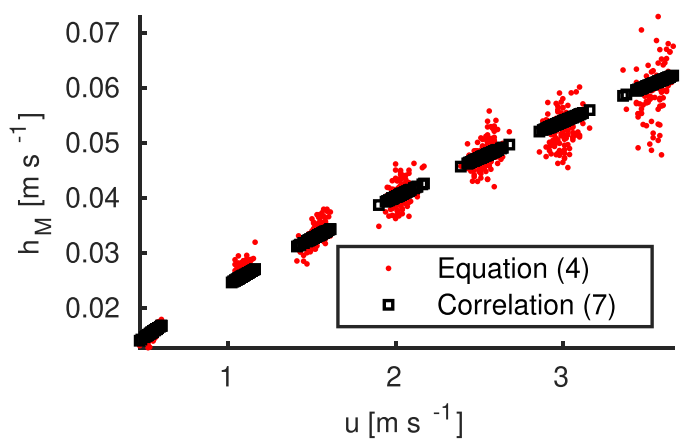

(c)

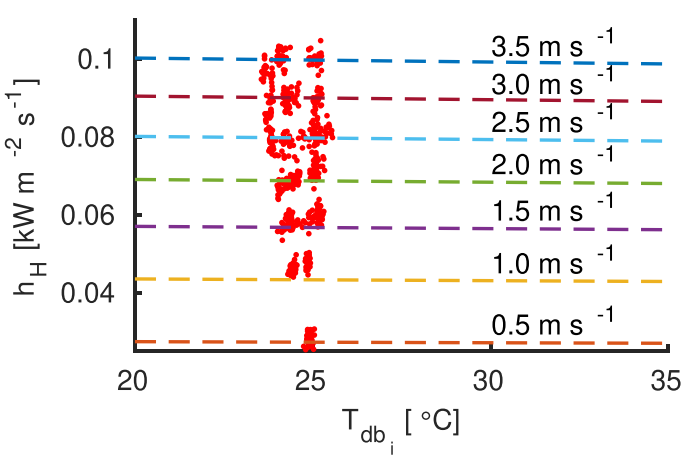

(b)

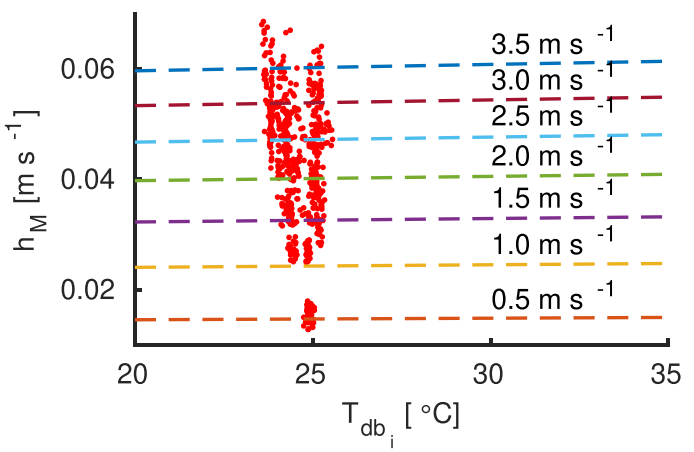

(d)

Fig. 4 - Relation between heat and mass transfer coefficients $\left(h_{H}\right.$ and $\left.h_{M}\right)$ with air velocity $(u)$ and input dry-bulb temperature $\left(T_{d b_{i}}\right)$ at using different expressions to compute them. (a) - Heat transfer coefficient vs. input air velocity. (b) - Heat transfer coefficient vs. input dry-bulb temperature. (c) - Heat transfer coefficient vs. input air velocity. (d) - Mass transfer coefficient vs. input dry-bulb temperature. The water temperature was considered equal to the air input wet-bulb temperature. 


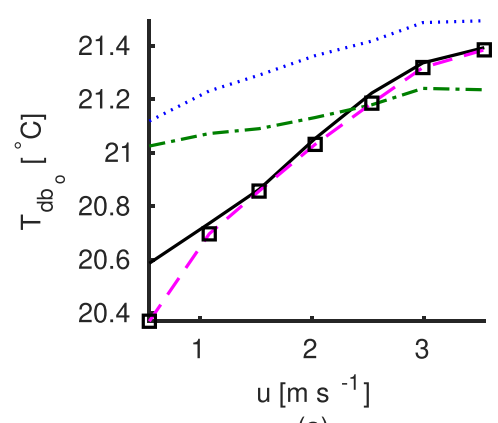

(a)

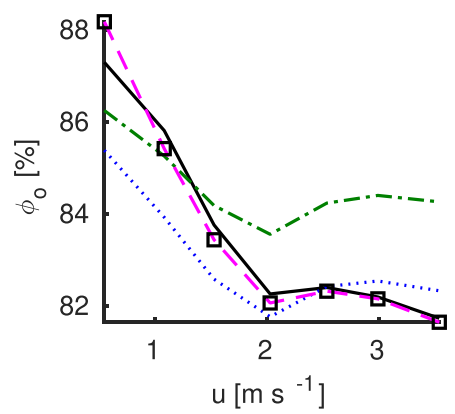

(b)

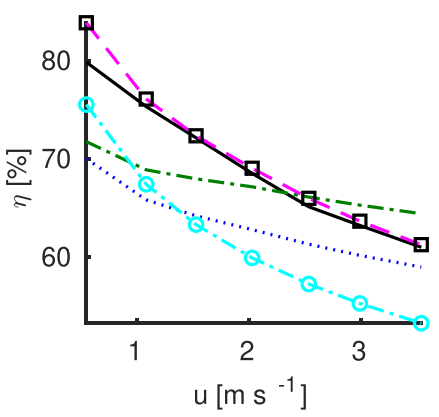

(c)

Fig. 5 - Effect of the input air velocity over the main output variables of the evaporative pad cooling. (a) - Output dry-bulb temperature $\left(T_{d b_{0}}\right)$. (b) - Output relative humidity $\left(\varphi_{0}\right)$ and $(\mathbf{c})$ - Cooling efficiency $(\eta)$. Solid line: Experimental data. Dashed line with square markers: Correlation (7). Dash-dot line: Franco et al. (2010). Dotted line: Dowdy and Karabash (1987). Dashdot line with circle markers: Manufacturer cooling efficiency.

Table 3 - RMSE values of predictions of the proposed model in function of the water flow $\left(Q_{1}=1.1 \mathrm{~L} \mathrm{~s}^{-1}, \mathrm{Q}_{2}=3.1 \mathrm{~L} \mathrm{~s}{ }^{-1}\right.$ and $Q_{3}=5.2 \mathrm{~L} \mathrm{~s}^{-1}$ ); and average RMSE values for the different methods used to compute the heat and mass transfer coefficients.

\begin{tabular}{|c|c|c|c|c|c|c|c|c|c|c|c|c|}
\hline & \multicolumn{4}{|c|}{$\operatorname{RMSE}_{T_{d b_{o}}}\left[{ }^{\circ} \mathrm{C}\right]$} & \multicolumn{4}{|c|}{$\operatorname{RMSE}_{\varphi_{o}}[\%]$} & \multicolumn{4}{|c|}{$\operatorname{RMSE}_{\eta}[\%]$} \\
\hline & $Q_{1}$ & $\mathrm{Q}_{2}$ & $\mathrm{Q}_{3}$ & Aver. & $\mathrm{Q}_{1}$ & $\mathrm{Q}_{2}$ & $\mathrm{Q}_{3}$ & Aver. & $Q_{1}$ & $\mathrm{Q}_{2}$ & $\mathrm{Q}_{3}$ & Aver. \\
\hline Expression (7) & 0.04 & 0.11 & 0.04 & 0.06 & 0.23 & 0.59 & 0.27 & 0.36 & 0.83 & 2.03 & 0.71 & 1.19 \\
\hline Expression (8) & 0.04 & 0.11 & 0.04 & 0.06 & 0.23 & 0.59 & 0.26 & 0.36 & 0.83 & 2.04 & 0.71 & 1.19 \\
\hline Franco et al. (2010) & 0.20 & 0.25 & 0.17 & 0.21 & 1.72 & 1.71 & 2.05 & 1.82 & 4.01 & 4.73 & 2.86 & 3.87 \\
\hline Dowdy and Karabash (1987) & 0.32 & 0.36 & 0.35 & 0.34 & 0.78 & 1.14 & 0.60 & 0.84 & 6.70 & 6.77 & 5.93 & 6.47 \\
\hline
\end{tabular}

Wilcoxon signed-rank test, presented under the median values (solid line), indicate that the model predictions with the correlation proposed here are in agreement with the wind tunnel measurements $(p>0.05)$. Furthermore, the $p$-values less than 0.05 indicate that $T_{d b_{0}}$ and $\varphi_{0}$ predictions with the correlations proposed by Franco et al. (2010) and Dowdy and Karabash (1987) are statistically different from the wind tunnel measurements. It is also shown that $T_{d b_{o}}$ and $\varphi_{o}$ are overestimated by the correlations of Franco et al. (2010) and Dowdy and Karabash (1987), respectively. This causes an underestimation of $\eta$, with an increasing in the median value up to $4.7 \%$ for the correlations of Dowdy and Karabash (1987).

\subsection{Wind tunnel evaporative test}

This test allows the real evaporated water to be compared with the model predictions. It was made with a constant air velocity of $1 \mathrm{~m} \mathrm{~s}^{-1}$ and water flow of $3.2 \mathrm{~L} \mathrm{~min}^{-1}$. The RMSE values presented in Table 4 confirm that the correlations proposed here exhibit the best prediction of $T_{d b_{0}}$ and consequently of $\eta$. Meanwhile, the correlation proposed by Franco et al. (2010) presents the best prediction of $\varphi_{0}$, although not so far from the predicted values from the correlations (7) and (8).

Figure $7 \mathrm{a}$ shows the evaporation mass flow rate $\left(\dot{m}_{e}\right)$ computed using equation (A.6). $\dot{m}_{e}$ predicted by all the methods was higher that the experimental values, with the correlation (7) and (8) giving the best predictions. The quantity of water evaporated was computed over $\dot{m}_{e}$ using the trapezoidal numeric integration method. Comparison between the amount of water evaporated during the experiment in the wind tunnel and predicted by the proposed model are shown in Fig. 7b. The amount of water evaporated is overestimated by all the correlations used, but the correlations proposed in this study gave values closer to the experimental data. At $2 \mathrm{~h}$ of operation, $2.66 \mathrm{~L}$ of water were evaporated and the predicted values were $0.1 \mathrm{~L}(3.8 \%), 0.6 \mathrm{~L}(22.6 \%)$ and $0.8 \mathrm{~L}(30.1 \%)$ larger, for the correlations proposed here, Dowdy and Karabash (1987) and Franco et al. (2010), respectively.

The proposed mathematical model can be used to predict the quantity of evaporated water, considering that the prediction errors will increase with time simulation. Selecting one appropriated method to compute the heat and mass transfer coefficients as a function of the characteristics of the cooling pad analysed will reduce the magnitude of error prediction. The results obtained with the correlations proposed here could be used as an upper boundary of the quantity of water evaporated by the cooling pad.

\subsection{Closed dairy cattle building model prediction}

The predictions of one day of experimental data from the closed dairy cattle building with evaporative pad cooling are shown in Fig. 8. As both correlations proposed here give the same prediction results, only the correlation (7) was analysed. This gave the best predictions for all the output variables: drybulb temperature $\left(T_{d b_{0}}\right)$, relative humidity $\left(\varphi_{0}\right)$ and pad cooling efficiency $(\eta)$; the RMSE values shown in Table 5 confirm this statement. Additionally, the RMSE values are less that the accuracy of the sensors used. The proposed model adequately describes the dynamic of the output variables. The predictions of $\mathrm{T}_{d b_{0}}, \varphi_{\mathrm{o}}$ and $\eta$ present maximum errors of $\pm 0.5{ }^{\circ} \mathrm{C}, \pm 1.4 \%$ and $\pm 8 \%$, respectively. It was found that the correlation (7) tended to overestimate $T_{d b_{0}}$ and underestimate $\varphi_{0}$ and $\eta$ up to the maximum errors mentioned before. 


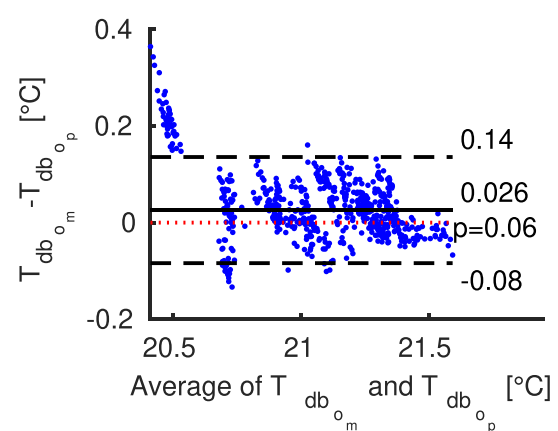

(a)

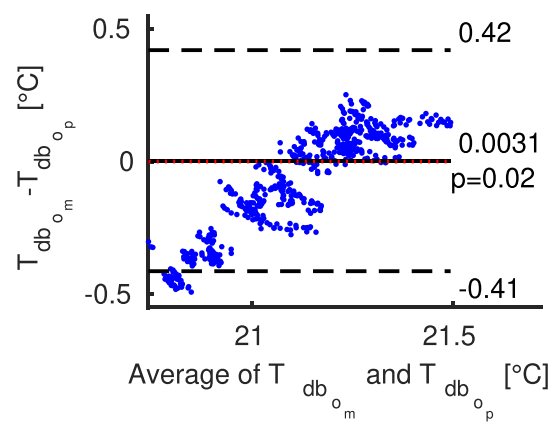

(d)

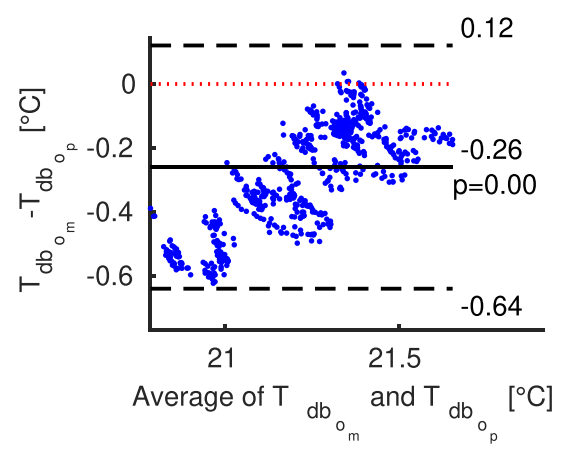

(g)

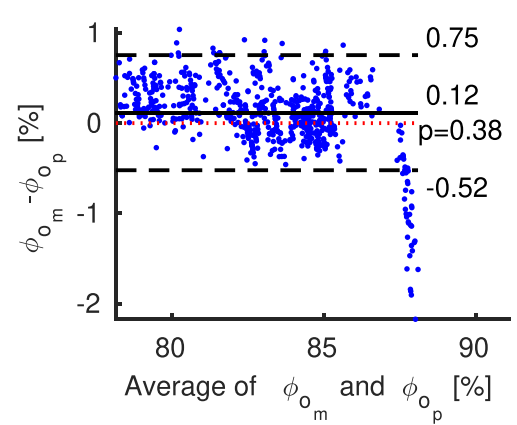

(b)

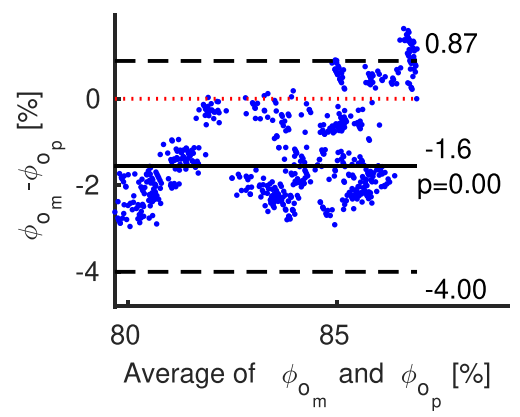

(e)

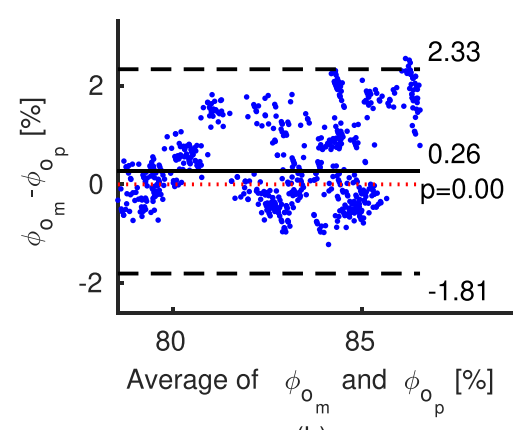

(h)

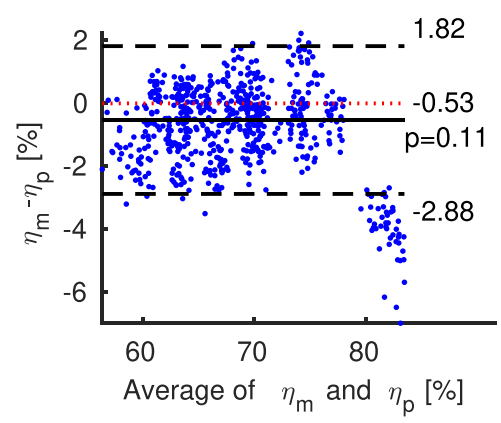

(c)

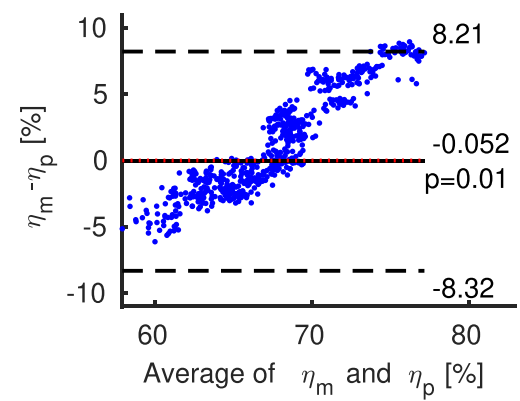

(f)

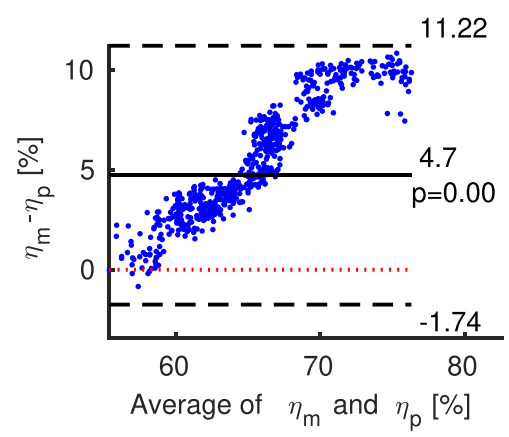

(i)

Fig. 6 - Bland and Altman plots for wind tunnel measurements $(m)$ and model predictions $(p)$ for output dry-bulb temperature $\left(T_{d b_{0}}\right)$, output relative humidity $\left(\varphi_{0}\right)$ and cooling efficiency $(\eta)$ when using different methods to compute the heat and mass transfer coefficient. (a), (b) and (c) - Using proposed correlations (7). (d), (e) and (f) - Using correlations of Franco et al. (2010) and (g), (h) and (i) - Using correlations of Dowdy and Karabash (1987). Horizontal axis corresponds to the average value between the measurements and model predictions; vertical axis corresponds to prediction residuals computed as the difference between measurements and model predictions; solid line corresponds to median value, and dashed lines correspond to agreement limits; $p$-values computed with the Wilcoxon signed-rank test are shown under the median value.

Table 4 - RMSE values of the wind tunnel evaporation test model results for the different methods used to computed the heat and mass transfer coefficients.

$h_{H}$ and $h_{M}$ computed $\operatorname{RMSE}_{T_{d b_{0}}}\left[{ }^{\circ} \mathrm{C}\right] \quad \operatorname{RMSE}_{\varphi_{0}}[\%] \quad \operatorname{RMSE}_{\eta}[\%]$ method

\begin{tabular}{llll} 
Correlation (7) & 0.14 & 0.47 & 2.8 \\
Correlation (8) & 0.14 & 0.47 & 2.8 \\
Franco et al. (2010) & 0.49 & 0.39 & 9.85 \\
Dowdy and & 0.64 & 1.62 & 12.66 \\
$\quad$ Karabash (1987) & & & \\
\hline
\end{tabular}

In the Bland and Altman plots shown in Fig. 9, it is evident that $T_{d b_{0}}$ is overestimated and $\varphi_{0}$ and $\eta$ are underestimated for the three correlations employed. The $T_{d b_{0}}$ and $\varphi_{0}$ residuals showed a random distribution around their median, while the $\eta$ prediction residuals showed a clear tendency to increase the underestimation for higher predicted values. For all correlations employed, the $p$-values are zero, indicating that the median of the measurements are statistically different $(\alpha$ equal to 0.05 ) from the prediction values. However, this is due to systematic errors represented by the displacement of the median of the residuals (solid line) from the zero line residual (dotted line). These deviations are smaller and the prediction agreement intervals (dashed lines) contain the zero line residual when the correlations proposed here are used.

The dispersion of the residuals are less than $0.68{ }^{\circ} \mathrm{C}$ and $2.92 \%$ for the prediction of $T_{d b_{0}}$ and $\varphi_{0}$, respectively. Indeed, the residuals are smaller than the accuracy of the sensors 


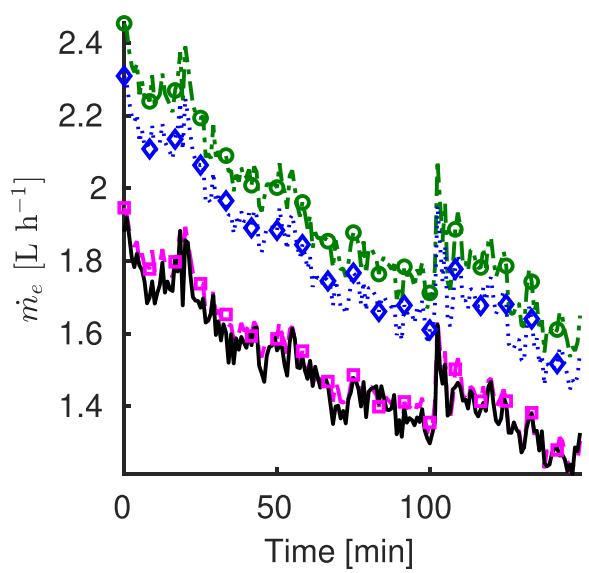

(a)

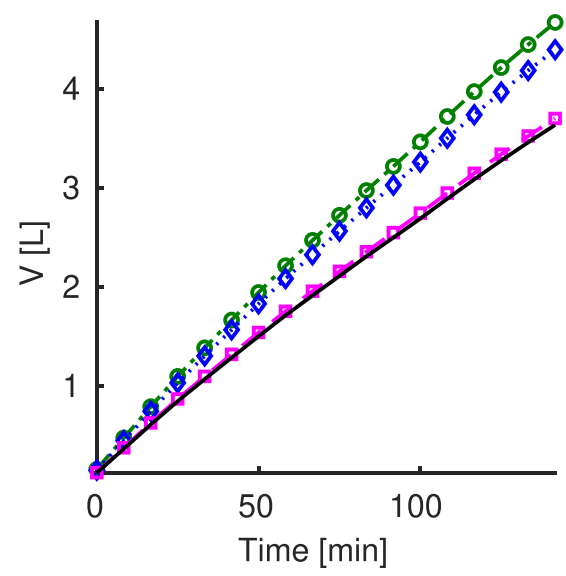

(b)

Fig. 7 - Evaporation mass water flow rate and water evaporated for the wind tunnel evaporative test. (a) - Evaporation mass water flow rate $\left[\mathrm{L} \mathrm{min}^{-1}\right]$. (b) - Volume of water evaporated [L] over time. The results for the correlations (7) and (8) are considered equal. Solid line: experimental data. Dashed line with square markers: Correlation (7). Dash-dot line with circle markers: Franco et al. (2010). Dotted line with diamond markers: Dowdy and Karabash (1987).

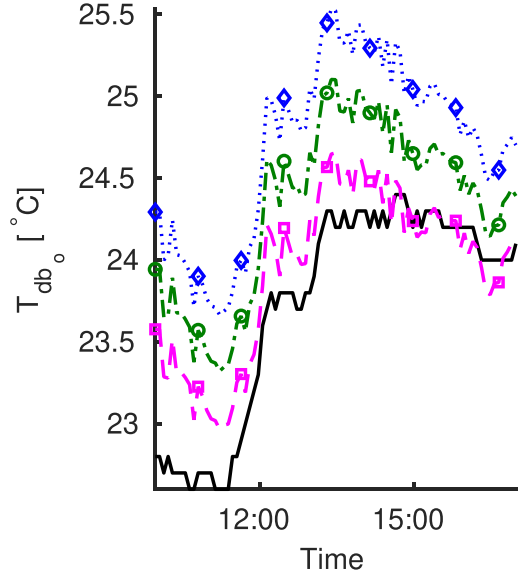

(a)

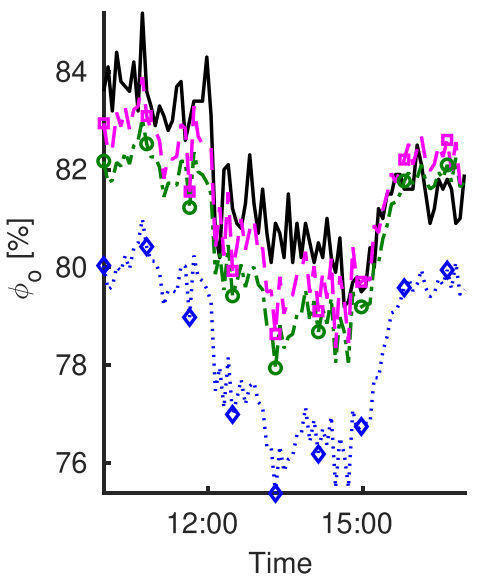

(b)

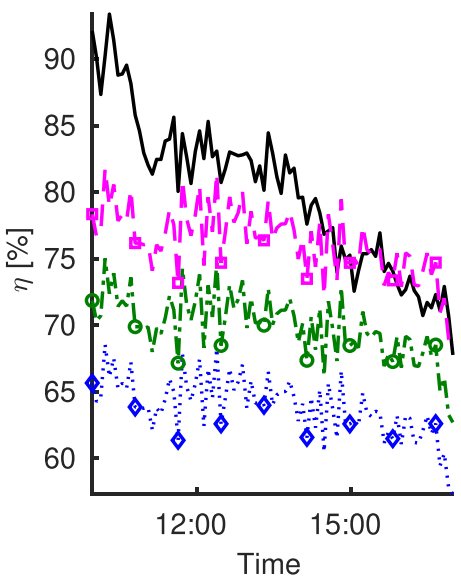

(c)

Fig. 8 - Measured and predicted values for the third day of experimental data from the closed dairy cattle building with evaporative pad cooling. (a) - Output dry-bulb temperature. (b) - Output relative humidity. (c) - Evaporative pad cooling efficiency. Solid line: experimental data. Dashed line with square markers: Correlation (7). Dash-dot line with circle markers: Franco et al. (2010). Dotted line with diamond markers: Dowdy and Karabash (1987).

used. This confirms that the proposed model presents good accuracy.

\subsection{Effect of pad water temperature on output} variables: a pad cooling model application

An important use that can be given to the cooling pad mathematical model presented here is to determine the effect of the pad water temperature over the cooling output variables at different environmental conditions. When the Bland and Altman plot is used to analyse the relation between the water temperature measured for both wind tunnel and closed dairy cattle building tests versus the input wet-bulb temperature $\left(T_{w b_{i}}\right)$ (Figure shown in Appendix D), it can be concluded that the water temperature tends to keep the input wet-bulb temperature at steady state cooling pad operation, as was argued by Liao et al. (1998) and Vijaykumar et al. (2015).
Simulations for differents $T_{d b_{i}}$ and two $\varphi_{i}$ values were carried out using the same cooling pad analysed in the wind tunnel tests. In the first simulation it is assumed that the water temperature is equal to $T_{w b_{i}}$ (solid line in Fig. 10), and in the second, it is assumed that the water temperature is cooled $1{ }^{\circ} \mathrm{C}$ below $\mathrm{T}_{w b_{i}}$ (dashed line in Fig. 10). Figure 10a and $\mathrm{d}$ shows

Table 5 - RMSE values of model predictions for all close dairy cattle installation tests.

\begin{tabular}{lccc}
$h_{H}$ and $h_{M}$ & $\operatorname{RMSE}_{T_{d b_{0}}}\left[{ }^{\circ} \mathrm{C}\right]$ & $\operatorname{RMSE}_{\varphi_{0}}[\%]$ & $\mathrm{RMSE}_{\eta}[\%]$ \\
$\begin{array}{l}\text { computed } \\
\text { method }\end{array}$ & & & \\
\hline Correlation (7) & 0.47 & 1.37 & 8.03 \\
Franco et al. (2010) & 0.82 & 2.01 & 13.76 \\
Dowdy and & 1.19 & 4.15 & 19.58 \\
$\quad$ Karabash (1987) & & & \\
\hline
\end{tabular}




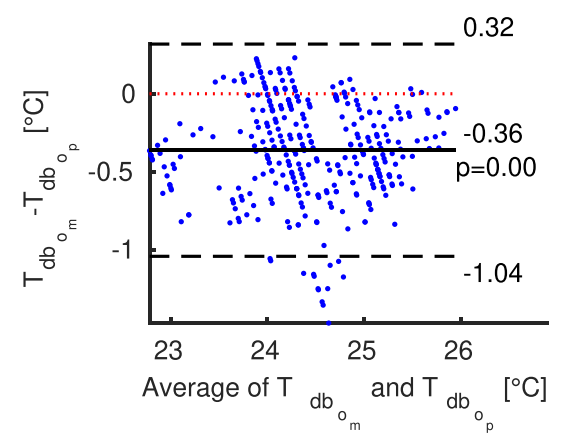

(a)

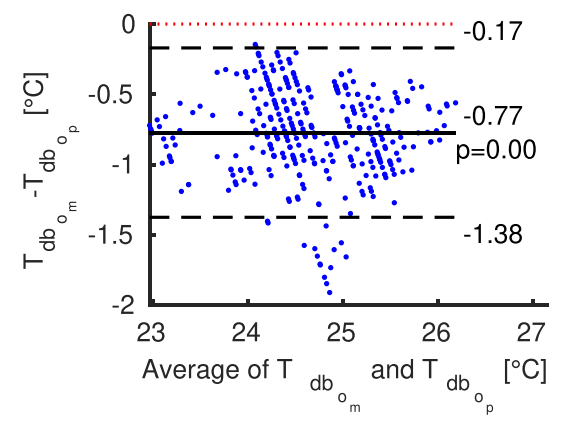

(d)

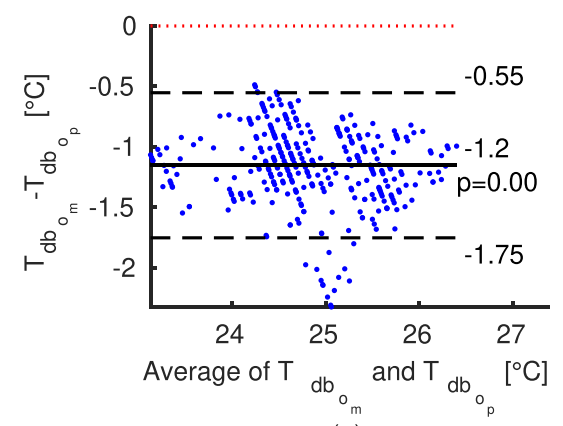

(g)

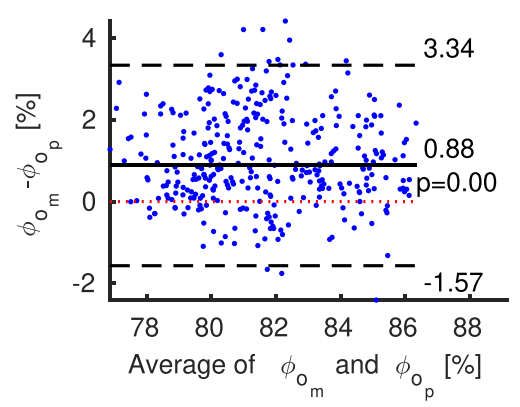

(b)

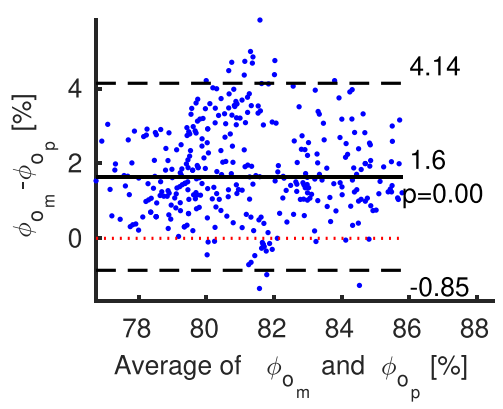

(e)

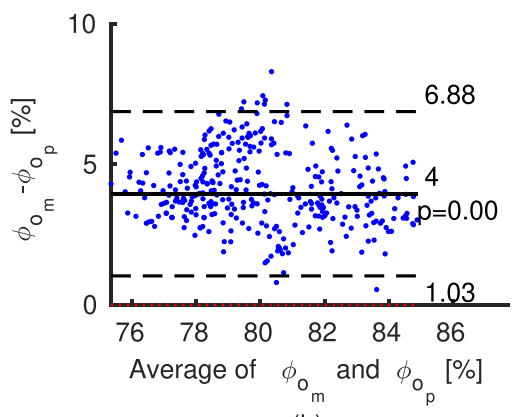

(h)

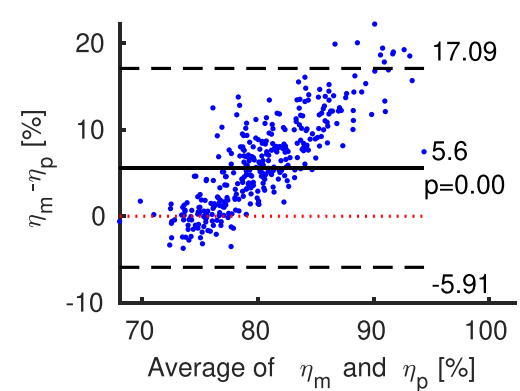

(c)

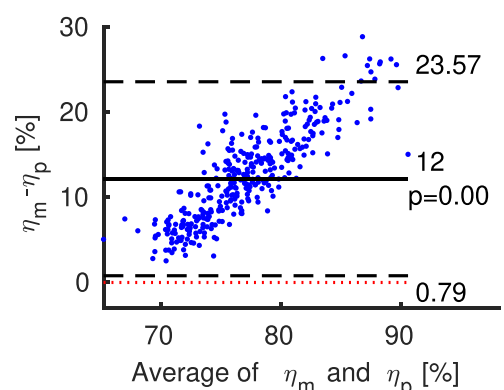

(f)

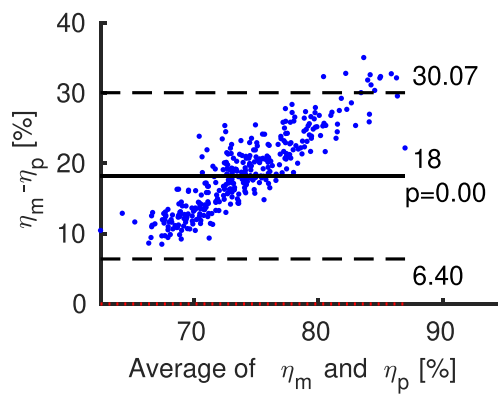

(i)

Fig. 9 - Bland and Altman plots for closed dairy cattle building measurements $(m)$ and model predictions $(p)$ for output drybulb temperature $\left(T_{d b_{0}}\right)$, output relative humidity $\left(\varphi_{0}\right)$ and cooling efficiency $(\eta)$ when using different methods to compute the heat and mass transfer coefficient. (a), (b) and (c) - Using proposed correlations (7). (d), (e) and (f) - Using correlations of Franco et al. (2010) and (g), (h) and (i) - Using correlations of Dowdy and Karabash (1987). Horizontal axis corresponds to the average value between the measurements and model predictions; vertical axis corresponds to prediction residuals computed as the difference between measurements and predicted values; solid line corresponds to median value, and dashed lines correspond to agreement limits; $p$-values computed with the Wilcoxon signed-rank test are shown under the median value.

the simulation results for $T_{d b_{0}}$ and $\varphi_{0}$, respectively. A visual inspection reveals a constant increment of $T_{d b_{0}}$ and $\varphi_{0}$ at increasing $T_{d b_{i}}$, due to the reduction of water temperature. Details of the changes in $T_{d b_{0}}\left(\Delta T_{d b_{0}}\right)$ and $\varphi_{o}\left(\Delta \varphi_{0}\right)$ computed as the difference between predictions with $T_{s}$ equal to $T_{w b_{i}}$ and $T_{s}$ equal to $T_{w b_{i}}-1{ }^{\circ} \mathrm{C}$ are shown in Fig. $10 \mathrm{~b}$ and e revealing that the effect of changing the water temperature can be considered $T_{d b_{i}}$ and $\varphi_{i}$ independent.

Figure 10c and $f$ shows the variation of $T_{d b_{o}}$ and $\varphi_{o}$ when reducing the water temperature below $T_{w b_{i}}\left(T_{s}=T_{w b_{i}}+\Delta T_{s}\right)$ for cooling pad input conditions of $30{ }^{\circ} \mathrm{C}$ and $60 \%$ for $\mathrm{T}_{d b_{i}}$ and $\varphi_{i}$, respectively. A linear decrease of $T_{d b_{0}}$ and a quadratic increase of $\varphi_{o}$ happens as the water temperature decreases below $T_{w b_{i}}$.
Although a considerable reduction of $T_{d b_{0}}$ is reached when the water temperature is lowered below $T_{w b_{i}}$, a non-desirable increase of $\varphi_{0}$ occurs. Actually, for the input air conditions simulated, a saturation of the humidity of the output air is reached when decreasing the water temperature $6{ }^{\circ} \mathrm{C}$ below $T_{w b_{i}}$. The decrease of the water temperature should be done according to the input relative humidity, because when reducing drastically the water temperature, the output relative humidity can easily exceed the recommended upper limit for the system. However, the water temperature can be considered as an effective variable that can be manipulated to increase the reduction of indoor temperature in facilities with evaporative pad cooling systems. 


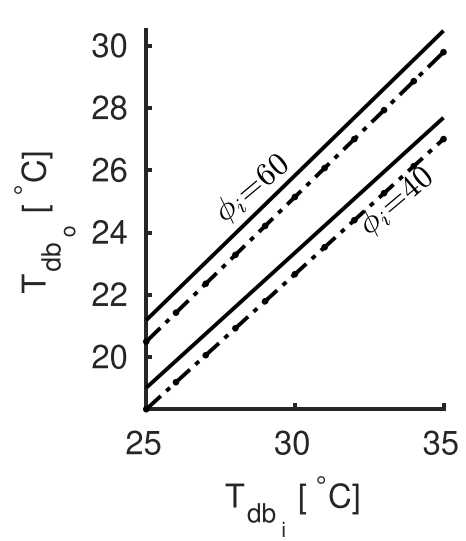

(a)

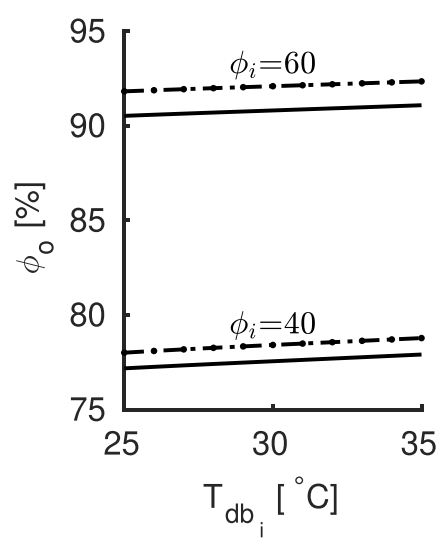

(d)

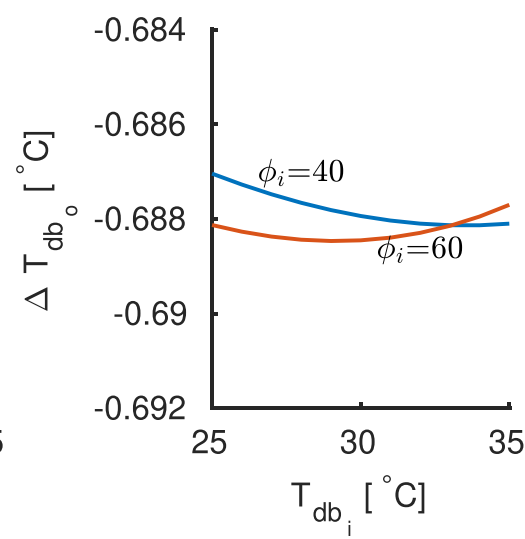

(b)

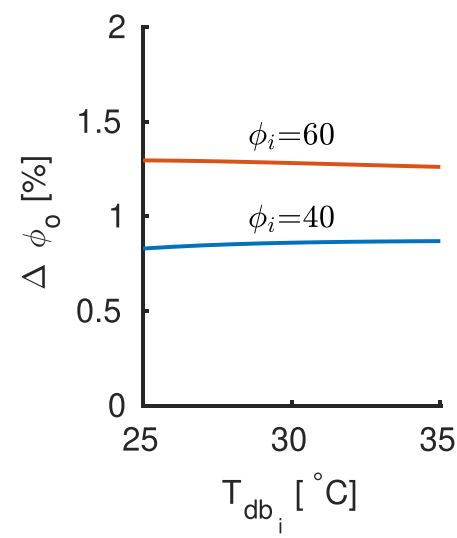

(e)

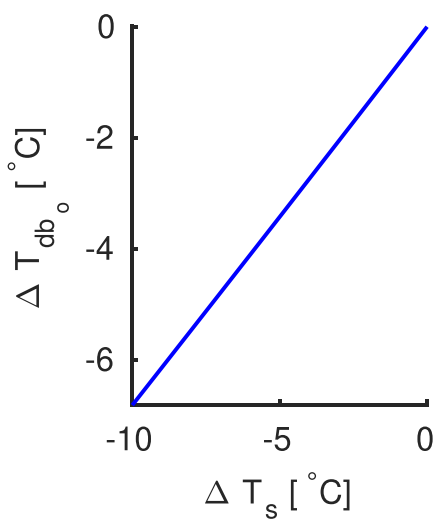

(c)

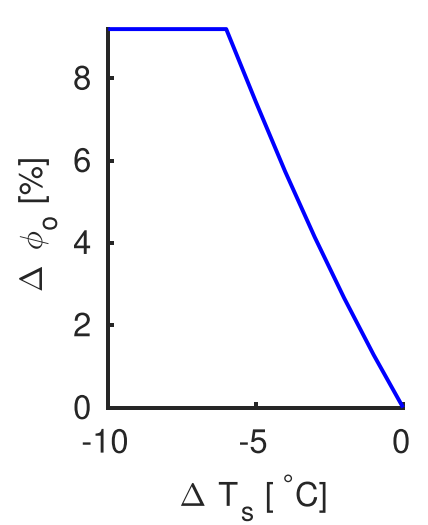

(f)

Fig. 10 - Effect of the reduction of the water temperature $\left(T_{s}\right)$ one Celsius degree below the input wet-bulb temperature $\left(T_{w b_{i}}\right)$ over the output dry-bulb temperature $\left(T_{d b_{o}}\right)$ and output relative humidity $\left(\varphi_{o}\right)$. (a) - Effect of $T_{s}$ over $T_{d b_{o}}$ for different input dry-bulb temperature $\left(T_{d b_{i}}\right)$ and two input relative humidities, $\varphi_{i}=40 \%$ and $\varphi_{i}=60 \%$. (b) - Difference between $T_{d b_{o}}$ computed with $T_{s}$ equal to $T_{w b_{i}}$ and $T_{d b_{o}}$ computed with $T_{s}$ equal to $T_{w b_{i}}-1{ }^{\circ} \mathbf{C}$ for the two $\varphi_{i}$ studied. (c) - Change in $T_{d b_{o}}$ at decreasing the $T_{s}$ below $T_{w b_{i}}\left(T_{s}=T_{w b_{i}}+\Delta T_{s}\right)$ for a pad cooling input conditions of $30{ }^{\circ} \mathbf{C}$ and $60 \%$ for $T_{d b_{i}}$ and $\varphi_{i}$, respectively. (d) - Effect of $T_{s}$ over $\varphi_{o}$ for different $T_{d b_{i}}$ and two input relative humidities, $\varphi_{i}=40 \%$ and $\varphi_{i}=60 \%$. (e) - Difference between $\varphi_{0}$ computed with $\mathbf{T}_{s}$ equal to $\boldsymbol{T}_{w b_{i}}$ and $\varphi_{0}$ computed with $\mathbf{T}_{s}$ equal to $\mathbf{T}_{w b_{i}}-1{ }^{\circ} \mathbf{C}$ for the two $\varphi_{i}$ studied. (f) - Change in $\varphi_{0}$ at decreasing the $T_{s}$ below $T_{w b_{i}}\left(T_{s}=T_{w b_{i}}+\Delta T_{s}\right)$ for a pad cooling input conditions of $30{ }^{\circ} \mathbf{C}$ and $60 \%$ for $T_{d b_{i}}$ and $\varphi_{i}$, respectively. Solid line: $T_{s}=$ $\mathrm{T}_{w b_{i}}$. Dash-dot line: $\mathrm{T}_{\mathrm{s}}=\mathrm{T}_{w b_{i}}-1{ }^{\circ} \mathrm{C}$.

4.

\section{Conclusions}

A general pad cooling mathematical model was developed. The prediction of the main output cooling variables, dry-bulb temperature, relative humidity and efficiency, was in agreement with wind tunnel and closed dairy cattle building validations. However, it was evident that the precision of model prediction depends of the heat and mass transfer coefficients used. Here, expressions based on the correlations of Hilpert and Zukauskas were developed to compute the heat and mass transfer coefficients for commercial cellulose pad cooling with $45^{\circ}$ and $15^{\circ}$ angles and compared with similar expressions proposed early by other authors for similar cellulose pad cooling. The expression proposed here showed better performance to predict the behaviour of the main output variables for the closed dairy cattle building, used as a validation test. Additionally, a new expression to compute the specific superficial area that included the differences in dimensions of the corrugated sheets due to the channel inclination angle, was proposed, improving the model accuracy. Meanwhile, using the proposed mathematical model of pad cooling, an analysis of the influence of the pad water temperature over the output dry-bulb temperature and output relative humidity was made, showing a considerable reduction of the output dry-bulb temperature at the expenses of an increase in the output relative humidity when decreasing the water temperature below the input wet-bulb temperature. From this, it is possible to consider the pad water temperature as an effective variable for developing an evaporative pad cooling control system. Finally, the proposed model could be used to compute an estimated lower boundary of the quantity of water evaporated. The proposed model prediction can be improved by developing expressions to compute the heat and mass transfer coefficients that integrate the water temperature, the input wet-bulb temperature or the input relative humidity variables explicitly. 


\section{Declaration of competing interest}

The authors declare that they have no known competing financial interests or personal relationships that could have appeared to influence the work reported in this paper.

\section{Appendix A. Evaporative pad cooling mathematical model}

An infinitesimal wetted surface area $\left(d A_{s}\right)$ at the interior of the pad cooling is considered in Fig. A.1a. It is supposed that this has a constant wetted surface of temperature $T_{S}$ and that the humid air film closer to the wetted surface is at a saturated absolute humidity $\omega_{s}$. Changes in the dry-bulb temperature $\left(\mathrm{dT}_{d b}\right)$ and absolute humidity $(\mathrm{d} \omega)$ of the air that go through the infinitesimal surface are produced by heat and mass transfer process due to the difference in temperature and absolute humidity between the humid air and the wetted surface.

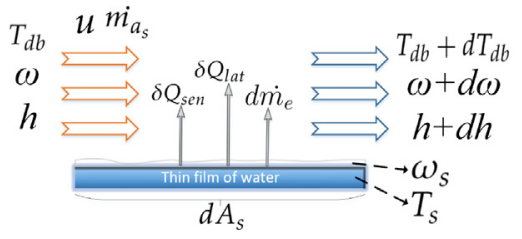

(a)

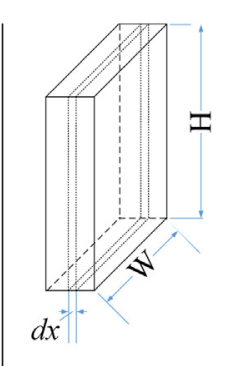

(b)
Fig. A.1 - Evaporative pad cooling model. (a) Infinitesimal portion of the cooling pad and the variables involved in the mass and energy transfer process. (b) Infinitesimal cooling pad volume.

If steady-state conditions are considered, water evaporation occurs when $T_{s}$ and $\omega_{s}$ are below $T_{d b}$ and $\omega$, respectively. Transfer of latent heat $\left(\delta \mathrm{Q}_{\text {lat }}\right)$ from the wetted surface to the humid air is present during this process and the energy required to maintain the evaporation is taken from the air, which in turn transfers sensible heat $\left(\delta Q_{\text {sen }}\right)$ to the wet surface, reducing the humid air temperature. A balance of energy made over the infinitesimal wetted surface relates the heat transfer with the humid air enthalpy change $(\mathrm{dh})$ and the humid air mass flow rate $\dot{m}_{a_{s}}$, as:

$\dot{m_{a_{s}}} \mathrm{dh}=\delta \mathrm{Q}_{\text {sen }}+\delta \mathrm{Q}_{\text {lat }}$

The humid air enthalpy $(h)$ is considered as a sum of the dry air enthalpy $\left(h_{a}\right)$ and water vapour enthalpy $\left(h_{v}\right)$ and can be expressed by the following expression (ASHRAE, 2009).

$h=h_{a}+\omega h_{v} \approx \mathrm{c}_{\mathrm{pa}} \mathrm{T}_{\mathrm{db}}+\omega \mathrm{h}_{\mathrm{g}} \approx \mathrm{c}_{\mathrm{pa}} \mathrm{T}_{\mathrm{db}}+\omega\left(\mathrm{c}_{\mathrm{pv} 0^{\circ} \mathrm{C}} \mathrm{T}_{\mathrm{db}}+\mathrm{h}_{\mathrm{g}_{\circledast 0} 0^{\circ} \mathrm{C}}\right)$

where $h_{g}$ is the saturated vapour enthalpy of water, $c_{p a}$ and $c_{p v}$ are the specific heat of dry air and water vapour, respectively, and the @ symbol indicate the temperature where the thermodynamic property should be evaluated. The last expression can be differenced to obtain the humid air enthalpy change as,

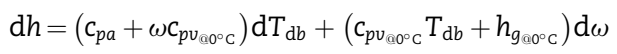

The sensible heat transferred from the humid air to the wet surface can be expressed using Newton's law; where $h_{H}$ is the heat transfer coefficient of the pad cooling material (Incropera et al., 2011).

$\delta \mathrm{Q}_{\mathrm{sen}}=h_{\mathrm{H}}\left(\mathrm{T}_{\mathrm{s}}-\mathrm{T}_{\mathrm{d} b}\right) \mathrm{d} \mathrm{A}_{\mathrm{s}}$

The latent heat is directly proportional to the water evaporation flow rate $\left(\mathrm{d} \dot{m}_{e}\right)$ multiplied by the energy required for the evaporation process, which is given by the vapour water enthalpy $\left(h_{v}\right)$ evaluated at the wetted surface temperature $\left(T_{s}\right)$ (Cengel and Boles, 2015). The latent heat transferred can then be expressed as,

$\delta Q_{\text {lat }}=h_{v_{@ T_{s}}} d \dot{m}_{e} \approx\left(c_{p v_{@ 0^{\circ} \mathrm{C}}} T_{\mathrm{s}}+h_{g_{\varrho 0^{\circ} \mathrm{C}}}\right) \mathrm{d} \dot{m}_{e}$

The infinitesimal water evaporation rate can be obtained analogously to Newton's law (Incropera et al., 2011),

$\mathrm{d} \dot{m}_{e}=h_{\mathrm{M}}\left(\rho_{v_{\mathrm{s}}}-\rho_{v}\right) \mathrm{d} \mathrm{A}_{\mathrm{s}}$

where $h_{M}$ is the mass transfer coefficient of the cooling pad material, $\rho_{v_{s}}$ is the saturated water vapour density at the wetted surface temperature and $\rho_{v}$ is the water vapour density of the humid air, which can be computed in terms of the relative humidity $(\varphi)$ and the saturate water vapour density as $\rho_{v}=\varphi \rho_{v_{@ T} d b}$ (Cengel and Boles, 2015). It can be expressed also as,

$\mathrm{d} \dot{m}_{e}=\dot{m_{a_{s}}} \mathrm{~d} \omega$

Substituting equations (A.3) to (A.7) in equation (A.1) equation (A.8) is obtained and from equations (A.6) and (A.7) equation (A.9) is obtained to compute the change in the humid air temperature and in the specific humidity through the infinitesimal wetted surface, respectively.

$\frac{\mathrm{dT}_{b s}}{\mathrm{~d} A_{s}}=\frac{\left(T_{s}-T_{d b}\right)\left(h_{H}+h_{M} c_{p v_{a 0}{ }^{\circ} \mathrm{C}}\left(\rho_{v_{s}}-\rho_{v}\right)\right)}{\dot{m}_{a_{s}}\left(c_{p a}+\omega c_{p v_{\dddot{0} 0} \mathrm{C}}\right)}$

$\frac{\mathrm{d} \omega}{\mathrm{dA} \mathrm{A}_{\mathrm{s}}}=\frac{h_{\mathrm{M}}\left(\rho_{v_{\mathrm{s}}}-\rho_{\mathrm{v}}\right)}{m_{a_{\mathrm{s}}}}$

The specific wetted surface area ( $\zeta)$ is a parameter that characterises the cooling pad material and it is defined as the total wetted surface area of the cooling pad over its volume. Now, taking a transversally section of the pad with an infinitesimal length $d x$ (Fig. A.1b) and considering that $T_{b s}$ and $\omega$ are distributed homogeneously along all the pad area, the wetted surface area of this volume could be computed as $\mathrm{dA}_{\mathrm{s}}=$ $\zeta \mathrm{W} \mathrm{H} \mathrm{dx}$. When this expression is replaced in equations (A.8) and (A.9), and supposing that the moist air mass flowing through the cross sectional area is equal to $\dot{m}_{a}$, the system of ordinary differential equations (ODEs) (1) is obtained.

\section{Appendix B. Numerical solution}

To determine the minimum number of partitions $(N)$ of the pad thickness that should be used by the RK4 method, a comparison of several numerical solutions obtained with 
different $N$ values was made. Equation (B.1) was employed to quantify the approximate deviation error $\left(\delta_{\Omega}\right)$ of the variable $\Omega$ at use an arbitrary $N$ value. $\Omega_{5000}$ and $\Omega_{N}$ are the numerical solutions of the output variables $\left(T_{d b_{0}}, \varphi_{o}\right.$ and $\left.\eta\right)$ for 5000 and $N$ partitions, respectively. It is assumed that the best numerical solution is obtained with 5000 partitions. Table B.1 shows that $\delta_{\varphi_{0}}$ presents the highest approximate deviation errors, but are below $0.01 \%$ when the number of partitions is above 250 . This number allows solving the proposed model with the RK4 method without loss of precision and less computational time. A particular solution of the proposed model using 250 partitions is presented in Fig. B.1. It is shown how the dry-bulb temperature and relative humidity change as a function of location inside the pad cooling system.

$\delta_{\Omega}=\frac{\Omega_{5000}-\Omega_{\mathrm{N}}}{\Omega_{5000}} * 100 \%$

\section{Appendix C. Thermodynamics properties}

To compute the thermodynamics properties of the saturated water and the dry air at 1 atmosphere of pressure, third degree polynomials were fitted to the data presented in table A- 4 of Cengel and Boles (2015) and table A-9 of Cengel and Cimbala (2005), obtaining the expressions (C.1) to (C.10), that can be used to compute them in terms of temperature $\left(T,{ }^{\circ} \mathrm{C}\right)$.

$$
\begin{aligned}
& h_{f}(T)=7.79 \times 10^{-6 *} T^{3}-0.0008507 * T^{2}+4.21 * T \\
& -0.006433\left[\mathrm{~kJ} \mathrm{~kg}^{-1}\right] \\
& h_{f g}(T)=-1.243 \times 10^{-5 *} T^{3}+0.0006317 * T^{2}-2.38 * T \\
& +2501\left[\mathrm{~kJ} \mathrm{~kg}^{-1}\right]
\end{aligned}
$$

Table B.1 - Approximate deviation of the numerical solution using different number of partitions (N) of the pad thickness with respect to the numerical solution obtained using 5000 partitions. The input conditions simulated were: $T_{d b_{i}}=24.4{ }^{\circ} \mathrm{C}$, $\varphi_{\mathrm{i}}=64 \%$ and $\mathrm{T}_{\mathrm{s}}=19.2{ }^{\circ} \mathrm{C}$.

\begin{tabular}{lccccccccc}
$N$ & 2 & 5 & 10 & 25 & 50 & 100 & 250 & 500 & 1000 \\
\hline$\delta_{T_{d b_{o}}}$ & 0.0099 & 0.0055 & 0.0027 & 0.0011 & 0.0005 & 0.0003 & 0.0001 & 0.0000 & 0.0000 \\
$\delta_{\varphi_{\varphi_{0}}}$ & 2.5504 & 0.9322 & 0.4526 & 0.1775 & 0.0878 & 0.0434 & 0.0168 & 0.0079 & 0.0035 \\
$\delta_{\eta}$ & 0.0671 & 0.0374 & 0.0185 & 0.0073 & 0.0036 & 0.0018 & 0.0007 & 0.0003 & 0.0001 \\
\hline
\end{tabular}

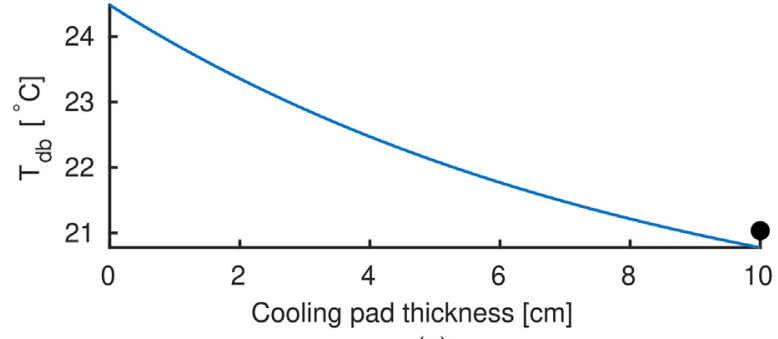

(a)

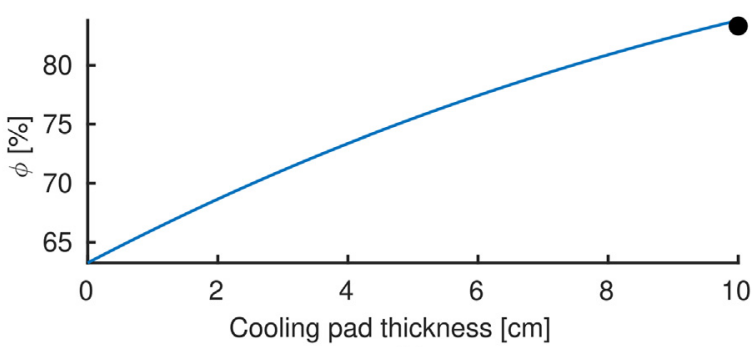

(b)

$$
\begin{aligned}
h_{g}(T)= & -1.368 \times 10^{-5} * T^{3}+0.0004312 * T^{2}+1.818 * T \\
& +2501\left[\mathrm{~kJ} \mathrm{~kg}^{-1}\right]
\end{aligned}
$$$$
P_{\text {sat }}(\mathrm{T})=7.973 \times 10^{-5} * \mathrm{~T}^{3}+-0.0007701 * \mathrm{~T}^{2}+0.07618 * \mathrm{~T}
$$$$
+0.4839[\mathrm{kPa}]
$$$$
\rho_{v_{\text {sat }}}(T)=4.585 \times 10^{-7 * T^{3}}+-1.36 \times 10^{-6 * T^{2}}+0.0004991 * T
$$$$
+0.004196\left[\mathrm{~kg} \mathrm{~m}^{-3}\right]
$$

$$
\begin{aligned}
& \rho_{a}(\mathrm{~T})=-3.419 \times 10^{-8 *} * \mathrm{~T}^{3}+1.576 \times 10^{-5} * \mathrm{~T}^{2}-0.004703 * \mathrm{~T} \\
& +1.292\left[\mathrm{~kg} \mathrm{~m}^{-3}\right]
\end{aligned}
$$$$
\mu(\mathrm{T})=3.263 \times 10^{-13} * \mathrm{~T}^{3}+-6.69 \times 10^{-11} * \mathrm{~T}^{2}+4.933 \times 10^{-8 * \mathrm{~T}}
$$$$
+1.729 \times 10^{-5}\left[\mathrm{~kg} \mathrm{~m}^{-1} \mathrm{~s}^{-1}\right]
$$

Fig. B.1 - Numerical solution of the proposed model. (a) Change of the dry-bulb temperature through the cooling pad. (b) - Change of the relative humidity through the cooling pad. • represents the experimental dry-bulb

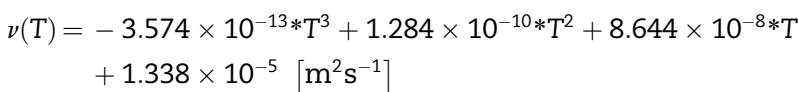
temperature and relative humidity measured at pad output.

$$
\begin{aligned}
& k(T)=-4.196 \times 10^{-10 * T^{3}}+8.159 \times 10^{-9} * T^{2}+7.489 \times 10^{-5 *} \mathrm{~T} \\
& +0.02364\left[\mathrm{~W} \mathrm{~m}{ }^{-1} \mathrm{~K}^{-1}\right]
\end{aligned}
$$




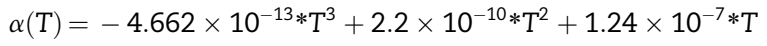

$$
\begin{aligned}
& +1.818 \times 10^{-5}\left[\mathrm{~m}^{2} \mathrm{~s}^{-1}\right]
\end{aligned}
$$

The specific heat of dry air $\left(c_{p_{a}}\right)$ and specific heat of water vapour $\left(c_{p_{v}}\right)$ in $\left[\mathrm{kJ} \mathrm{kg}^{-1} \mathrm{~K}^{-1}\right]$ were compute in terms of temperature $\left(\mathrm{T},{ }^{\circ} \mathrm{C}\right.$ ) using equations (C.11) and (C.12) (Cengel and Boles, 2015).

$$
\begin{aligned}
\mathrm{T}_{w b}(\mathrm{~T}, \varphi)= & \mathrm{T}^{*} \tan ^{-1}\left(0.151977 *(\varphi+8.313659)^{0.5}\right) \\
& +\tan ^{-1}(\mathrm{~T}+\varphi)-\tan ^{-1}(\varphi-1.676331) \\
& +0.00391838^{*} \varphi^{1.5} \tan ^{-1}\left(0.023101^{*} \varphi\right) \\
& -4.686035
\end{aligned}
$$

Finally, to compute the water vapour density at nonsaturated state, the specific humidity and relative humidity, the equation (C.15), (C.16) and (C.17) were used (Cengel and Boles, 2015).

$c_{p_{a}}=\frac{28.11+0.1967 \times 10^{-2 *}(\mathrm{~T}+273.15)+0.4802 \times 10^{-5 *}(\mathrm{~T}+273.15)^{2}-1.0966 \times 10^{-9 *}(\mathrm{~T}+273.15)^{3}}{28.9645}$

$c_{p_{v}}=\frac{32.24+0.1923^{-2 *}(T+273.15)+1.055^{-5 *}(T+273.15)^{2}-3.595 \times 10^{-9 *}(T+273.15)^{3}}{18.015}$

The Equation (C.13) was used to compute the mass diffusivity of water vapour in terms of temperature $\left[{ }^{\circ} \mathrm{C}\right]$; where $P$ corresponds to the total pressure [Pa] (ASHRAE, 2009).

$D_{A B}=\frac{0.926}{1 \times 10^{6} \mathrm{P}}\left[\frac{(\mathrm{T}+273.15)^{2.5}}{\mathrm{~T}+273.15+245}\right] \quad\left[\mathrm{m}^{2} \mathrm{~s}^{-1}\right]$

To compute the wet-bulb temperature in terms of air temperature (T) and relative humidity $(\varphi)$, the equation (C.14) proposed by Stull (2011) was used.

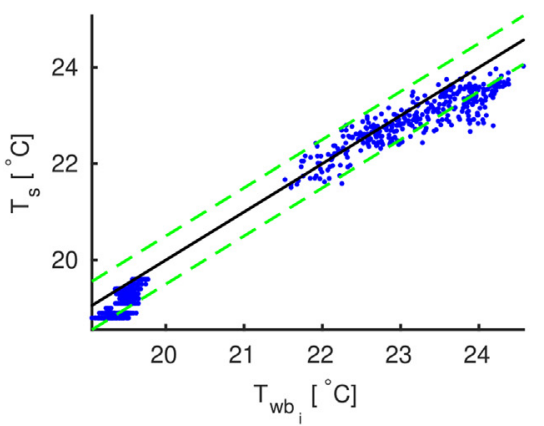

(a)

$$
\begin{aligned}
& \rho_{v}(\mathrm{~T}, \varphi)=\frac{\varphi}{100} * \rho_{v_{\text {sat }}}(\mathrm{T}) \\
& \omega(\mathrm{T}, \varphi)=\frac{0.622 \frac{\varphi}{100} \mathrm{P}_{\text {sat }}(\mathrm{T})}{\mathrm{P}-\frac{\varphi}{100} \mathrm{P}_{\text {sat }}(\mathrm{T})} \\
& \varphi(\mathrm{T}, \omega)=\frac{\omega}{(0.622+\omega) \mathrm{P}_{\text {sat }}(\mathrm{T})}
\end{aligned}
$$

\section{Appendix D. Water temperature figure}

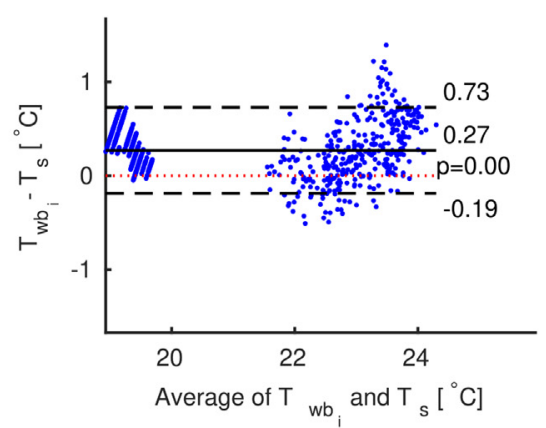

(b)

Fig. D.1 - Relation between water temperature $\left(T_{s}\right)$ and input wet-bulb temperature $\left(T_{w b_{i}}\right)$ for the wind tunnel and dairy cattle building tests. (a) - Plot of water temperature versus input wet-bulb temperature. Solid line corresponds to equality line and dashed lines correspond to the accuracy sensors limits. (b) - Bland and Altman plot. Horizontal axis corresponds to average value between the input wet-bulb air temperature and the water temperature; vertical axis corresponds to prediction residuals computed as the difference between input wet-bulb temperature and water temperature; solid line corresponds to median value, and dashed lines correspond to agreement limits; $p$-values computed with the Wilcoxon signed-rank test are shown under the median value. 


\section{R E F E R E N C E S}

Al-Ismaili, A. M., Weatherhead, E. K., \& Badr, O. (2010). Validation of Halasz's non-dimensional model using cross-flow evaporative coolers used in greenhouses. Biosystems Engineering, 107(2), 86-96. https://doi.org/10.1016/ j.biosystemseng.2010.07.004. URL.

ASABE. (2008). ANSI/ASAE EP406.4 JAN2003 (R2008) heating, ventilating and cooling greenhouses.

ASHRAE. (2009). 2009 ASHRAE handbook: Fundamentals. ASHRAE. ASHRAE. (2011). 2011 ASHRAE handbook - HVAC applications.

Camargo, J. R., Ebinuma, C. D., \& Cardoso, S. (2005a). A mathematical model for direct evaporative cooling air conditioning system. Revista de Engenharia Térmica, 2(2), 30-34. URL http://ojs.c3sl.ufpr.br/ojs2/index.php/reterm/article/ view/3473.

Camargo, J. R., Ebinuma, C. D., \& Silveira, J. L. (2005b). Experimental performance of a direct evaporative cooler operating during summer in a Brazilian city. International Journal of Refrigeration, 28(7), 1124-1132.

Cengel, Y. A., \& Boles, M. A. (2015). Thermodynamics: An engineering approach (8th ed.). New York: McGraw-Hill Education.

Cengel, Y. A., \& Cimbala, J. M. (2005). Fluid mechanics: Fundamentals and applications. McGrawHill.

Chen, Q., Pan, N., Guo, Z.-Y., \& may. (2011). A new approach to analysis and optimization of evaporative cooling system II: Applications. Energy, 36(5), 2890-2898. URL http://www. sciencedirect.com/science/article/pii/S0360544211001095.

de Carvalho, V. F., Yanagi, T., Yanagi, S. N. M., \& Damasceno, F. A. (2006). Modelagem da eficiencia de resfriamento evaporativo em sistemas de placas porosas umedecidas. In XXXV Congresso Brasileiro de Engenharia Agrícola. No. Julio-Agosto.

Dowdy, J. A., \& Handy, E. T. (1986). Heat- and mass-transfer coefficients. ASHRAE Transactions, 92(2), 60-70.

Dowdy, J. A., \& Karabash, N. S. (1987). Experimental determination of heat and mass transfer coefficients in rigid impregnated cellulose evaporative media. ASHRAE Transactions, 93(2), 382-395.

Fouda, A., \& Melikyan, Z. (2011). A simplified model for analysis of heat and mass transfer in a direct evaporative cooler. Applied Thermal Engineering, 31(5), 932-936. URL http://linkinghub. elsevier.com/retrieve/pii/S1359431110004965.

Franco, A., Valera, D. L., Madueño, A., \& Peña, A. (2010). Influence of water and air flow on the performance of cellulose evaporative cooling pads used in mediterranean greenhouses. Transactions of the ASABE, 53(March), 565-576.

Franco, A., Valera, D. L., \& Peña, A. (2014). Energy efficiency in greenhouse evaporative cooling techniques: Cooling boxes versus cellulose pads. Energies, 7(3), 1427-1447. URL http:// www.mdpi.com/1996-1073/7/3/1427/.

Giavarina, D. (2015). Understanding Bland Altman analysis. Biochemia Medica, 25(2), 141-151.
Halasz, B. (1998). A general mathematical model of evaporative cooling devices. Revue Générale de Thermique, 37(4), 245-255. URL http://www.sciencedirect.com/science/article/pii/ S0035315998800925.

He, S., Gurgenci, H., \& Alkhedhair, A. M. (2014). Experimental study of heat transfer coefficient and pressure drop of cellulose corrugated media. In 19th Australasian Fluid Mechanics Conference. Melbourne, Australia.

Incropera, F. P., Dewitt, D. P., Lavine, A. S., \& Bergman, T. L. (2011). Fundamentals of heat and mass transfer (7th ed.). John Wiley \& Sons, Ltd.

Kovacevic, I., \& Sourbron, M. (2017). The numerical model for direct evaporative cooler. Applied Thermal Engineering, 113, 8-19.

Liao, C. M., \& Chiu, K. H. (2002). Wind tunnel modeling the system performance of alternative evaporative cooling pads in Taiwan region. Building and Environment, 37, 177-187.

Liao, C.-M., Singh, S., \& Wang, T.-S. (1998). Characterizing the performance of alternative evaporative cooling pad media in thermal environmental control applications. Journal of Environmental Science and Health, Part A, 33(7), 1391-1417. URL http://www.tandfonline.com/doi/abs/10.1080/ 10934529809376795.

Malli, A., Seyf, H. R., Sharifian, S., Layeghi, M., \& Behravesh, H. (2011). Investigating the performance of cellulosic evaporative cooling pads. Energy Conversion and Management, 52, 2598-2603.

Osorio Saraz, J. A., Ferreira Tinoco, I.d. F., Oliveira Rocha, K. S., Arêdes Martins, M., \& Damasceno, F. A. (2012). Validation of a CFD model for prediction of the efficiency of evaporative cooling in porous panel. Revista U.D.C.A Actualidad \& Divulgación Científica, 15(1), 209-217.

Shukla, A., Tiwari, G. N., \& Sodha, M. S. (2008). Experimental study of effect of an inner thermal curtain in evaporative cooling system of a cascade greenhouse. Solar Energy, 82, 61-72.

Stull, R. (2011). Wet-bulb temperature from relative humidity and air temperature. Journal of Applied Meteorology and Climatology, 50(11), 2267-2269.

Vijaykumar, K. N., Kulkarni, M. M., Jadhav, N. A., Bhor, M. J., \& Shinde, S. S. (2015). Experimental performance evaluation of new cooling pad material for direct evaporating cooling for pune summer conditions. International Journal of Engineering Trends and Technology (IJETT), 22(6), 281-287.

Wu, J. M., Huang, X., \& Zhang, H. (2009a). Numerical investigation on the heat and mass transfer in a direct evaporative cooler. Applied Thermal Engineering, 29(1), 195-201. URL http:// linkinghub.elsevier.com/retrieve/pii/S1359431108000938.

Wu, J. M., Huang, X., \& Zhang, H. (2009b). Theoretical analysis on heat and mass transfer in a direct evaporative cooler. Applied Thermal Engineering, 29(5-6), 980-984. https://doi.org/10.1016/ j.applthermaleng.2008.05.016. URL. 